IZA DP No. 9940

Migrant Workers and the Welfare State

Torben M. Andersen

Silvia Migali

May 2016 


\title{
Migrant Workers and the Welfare State
}

\author{
Torben M. Andersen \\ Aarhus University \\ and IZA
}

Silvia Migali

University of Hagen

\section{Discussion Paper No. 9940 \\ May 2016}

\author{
IZA \\ P.O. Box 7240 \\ 53072 Bonn \\ Germany \\ Phone: +49-228-3894-0 \\ Fax: +49-228-3894-180 \\ E-mail: iza@iza.org
}

Any opinions expressed here are those of the author(s) and not those of IZA. Research published in this series may include views on policy, but the institute itself takes no institutional policy positions. The IZA research network is committed to the IZA Guiding Principles of Research Integrity.

The Institute for the Study of Labor (IZA) in Bonn is a local and virtual international research center and a place of communication between science, politics and business. IZA is an independent nonprofit organization supported by Deutsche Post Foundation. The center is associated with the University of Bonn and offers a stimulating research environment through its international network, workshops and conferences, data service, project support, research visits and doctoral program. IZA engages in (i) original and internationally competitive research in all fields of labor economics, (ii) development of policy concepts, and (iii) dissemination of research results and concepts to the interested public.

IZA Discussion Papers often represent preliminary work and are circulated to encourage discussion. Citation of such a paper should account for its provisional character. A revised version may be available directly from the author. 
IZA Discussion Paper No. 9940

May 2016

\section{ABSTRACT}

\section{Migrant Workers and the Welfare State}

There is wide concern that migration flows may undermine the financial viability of generous welfare arrangements. The discussion focuses on welfare arrangements as attractors of migrants, suggesting that the issue does not pertain to migrant workers. However, this overlooks how welfare arrangements affect return-migration in case of social events like job loss. Importantly, migrants are shown to be self-selected in a way affecting both migration and return-migration. Two migration regimes prevail. In one, with relatively low benefits, unemployed workers return, while in the other some stay. Importantly, the stay or return migration decision is more sensitive to welfare generosity than the migration decision.

JEL Classification: F22, J68, I31

Keywords: migrant workers, return-migration, job-loss, unemployment benefits

Corresponding author:

Torben M. Andersen

Department of Economics and Business Economics

Aarhus University

Fuglesangs Allé 4

8210 Aarhus V

Denmark

E-mail: tandersen@econ.au.dk 


\section{Introduction}

Debates on migration are divided between "labour" and "welfare" views. According to the "labour" view, differences in economic conditions may trigger migration flows, which therefore also work to mitigate such differences. This is e.g. ingrained in the EU internal market, which not only comprises free mobility of goods and capital but also labour. If labour migration responds to differences in wages and employment possibilities, it serves to reduce disparities in economic development. This may be an especially important adjustment mechanism within the European Monetary Union ${ }^{1}$. As a result of the internal market, there has been an increasing trend in labour migration within the EU, especially from the "new" to the "old" member states ${ }^{2}$.

The "welfare" view or concern is that migration flows are influenced by differences in welfare arrangements (welfare magnets) ${ }^{3}$. The welfare magnet hypothesis is about selection, see Borjas (1999). Do countries with more generous welfare arrangements on the one hand tend to attract immigrants benefitting from the welfare arrangements, and on the other hand to induce emigration of individuals being net contributors to the system? And do migrants, as a consequence, tend to rely more on welfare benefits than the rest of the population (welfare dependency)? If these mechanisms are strong, there are obvious implications for the financial viability of a generous welfare model ${ }^{4}$ (see e.g. Nannestad, 2007; Razin and Wahba, 2011). Accordingly, the social rights of migrant workers have become a controversial issue in the $\mathrm{EU}^{5}$.

The sharp distinction between "labour" and "welfare" migration in the debate may not be warranted for intra EU-migration. First, EU rules do not imply free mobility for "welfare" migrants ${ }^{6}$. Second, even if migrants are driven by a labour motive (ex ante), welfare arrangements may matter if exposed to events like unemployment (ex post). The important question is therefore which role welfare arrangements play for migrants' decision on possible return migration in case of unemployment or other social events. Focussing solely on the migration

\footnotetext{
${ }^{1}$ Since monetary policy by definition is common, labour migration is normally considered one of the conditions to ensure an "optimal currency area".

${ }^{2}$ The empirical evidence available for the crisis period suggests that no "mass return" took place in the EU in the wake of the financial crisis, see Zaiceva and Zimmermann (2012).

${ }^{3}$ It is here implicitly assumed that the welfare model is universal with tax financed provision of welfare services and the social safety net. Welfare arrangements more explicitly based on contributions may be less vulnerable to migration.

${ }^{4}$ These effects may also be important for migration rules, cf. e.g. Razin and Wahba, 2011. Within the EU free mobility of labour is ensured, but rules for migration from non-EU countries may be affected.

${ }^{5}$ Exemplified by the letter (2013) from the UK - supported by Germany, Austria and the Netherlands - to the EU - Commission demanding tighter restrictions on access to welfare benefits for migrants.

${ }^{6}$ According to EU directives migrants obtain full rights in another member state after five years of residence (three years for older citizens). Worker migration is unrestricted, and EU citizens who were workers or self-employed retain their status similar to that of other citizens even if they become temporarily unable to work due to e.g. illness or are involuntarily unemployed and searching for a job, see e.g. EEAG (2015). Non-worker migrants will not automatically obtain entitlements to welfare benefits.
} 
decisions may overlook an important mechanism whereby welfare arrangements and migration interact. While recognizing that migration may affect labour markets and welfare arrangements via different routes ${ }^{7}$, this paper focuses on the role of welfare entitlements for migrant workers. We explicitly model the decision to migrate for work, and the possible return migration ${ }^{8}$ in case of jobloss. As a measure of welfare state generosity, we use unemployment benefits, but it may be interpreted more widely as capturing the social insurance arrangements offered by the welfare state. Migration flows are not infinite, some find migration attractive and others do not (even for otherwise similar background factors). This is captured by assuming individual heterogeneity in the form of differences in migration costs.

We show that migration and return migration decisions are interrelated since migrants are self-selected among individuals with low migration costs. As a consequence, two different migration regimes may prevail depending on unemployment risks and unemployment benefits. In one regime (low benefits seen relative to unemployment risk), there is migration but all migrants return to their home country if becoming unemployed. In the other regime (high benefits seen relative to unemployment risk) some migrants return (low migration costs) while others stay (intermediary migration costs) if becoming unemployed. Importantly, we find in the second regime, that migration decisions are less sensitive to unemployment benefits than the return or stay migration decision. This points out that the traditional focus on how welfare arrangements may affect migration overlooks an important channel. The fact that return migration is affected by unemployment risks and benefit levels also suggests a possible asymmetry or path dependence in labour migration as an adjustment mechanism to differences in economic developments. In the first regime there is no such asymmetry, but there is in the second in the sense that there are welfare conditioned barriers for return migration.

To put this paper in perspective, a few remarks on the evidence on the role of migration for the financial viability of welfare arrangements are in place: there

\footnotetext{
${ }^{7}$ Collective agreements, minimum wages, labour market regulations etc. may also be affected.

${ }^{8}$ There exist only few theoretical studies of return migration. Borjas and Bratsberg (1994) argue that the return migration is part of an optimal life-cycle plan, and it can also occur when the migration decision is based on erroneous information about the destination country. In Dustmann (1997), the re-migration and consumption are jointly determined by immigrants, and he finds that the length of the stay in the host country is likely to increase when the wage differential and difference in labour market risk between the home and the host countries are relatively high. Dustmann (1999) finds that the time spent in the host country and the immigrants' propensity to return are connected to the immigrants' investment in human capital specific to the destination country. Dustmann and Gorlach (2016) model temporary migration decisions, finding that the length of the stay abroad (permanent or temporary) is influenced by different motives such as the preference for consumption in the home country, differences in purchasing power between the host and the home country, and positive wage differential in the origin country when immigrants have accumulated sufficient human capital. Mayr and Peri (2009) analyse the link between migration, return, and investment in schooling. They find that the possibility to migrate to countries with higher return to skills increases the incentive to invest in schooling. Such an investment and the return of educated migrants have positive effects on the average schooling of the sending country.
} 
is no strong evidence that welfare arrangements as such are an attractor or magnet (see Pedersen et al., 2008; Giuletti et al., 2014) ${ }^{9}$. Irrespective of the migration reason, public finances may, however, be affected. In countries with generous tax-financed welfare arrangements ${ }^{10}$, employment is the single most important determinant of migrants' net fiscal balance, see e.g. OECD (2013) and Hansen et al. (2015). Low employment rates for immigrants due to high entry wages, qualification barriers, gender differences and discrimination do have implications for public finances. For the same reason the fiscal implications vary significantly across migration groups. The empirical evidence suggests that the distinction between the ex ante and ex post effect of welfare arrangements is potentially important. Moreover, our analysis shows that cross-country evidence on magnet effects may be problematic, since countries may be in different migration regimes, where the role of welfare generosity on migration flows are non-monotone.

The paper is organized as follows: in Section 2 we provide some evidence on return migration motivating the analysis. In Section 3 we present the core model and work out the implications of unemployment benefits for migration and return-migration. To focus on the essential mechanisms, this model is very stylized, and Section 4 considers several generalizations of the model and shows that the basic insights stand. Section 5 offers a few concluding remarks.

\section{Return migration and welfare benefits}

Intra-EU labour mobility constitutes an obvious possibility to analyse the "welfare state-return migration" interactions. On the one hand, the absence of formal barriers to the internal mobility may prompt both the migration and re-migration of European immigrants. On the other hand, cross-country differences in terms of welfare state generosity can be observed among the EU Member States. Furthermore, for migrant labour access and participation to the welfare state systems are equally guaranteed to all EU citizens, and no formal discriminations are allowed.

Data limitations constrain the study of return migration ${ }^{11}$. Indeed, dif-

\footnotetext{
${ }^{9}$ There is some indication of "welfare magnet" effects between the "old" and "new" EU Member States (De Giorgi and Pellizzari, 2013), but in general this does not influence EU migration flows, (see Skupnik, 2014).

${ }^{10}$ This also points out that the effects are country-specific. Welfare dependency among immigrants has not been strongly supported by the empirical evidence for the EU (see Barrett and McCarhty, 2007; Giulietti, 2014), with the exception of Denmark and Sweden, (Giuletti, 2014). However, the dependency disappears when the unemployment risk of immigrants is taken into account, (Zimmermann et al., 2012). Country evidence indicates some welfare dependency in Denmark (Hansen et al., 2015), Germany (Riphahn, 2004), Sweden (Hansen and Lofstrom, 2009) and Italy (Pellizzari, 2013), but not in Ireland (Barrett et al., 2013).

${ }^{11}$ This is also the reason why empirical studies of return migration are scant. The existing literature is mainly cross-country studies on the return migration to the post-enlargement Member States (see Martin and Radu, 2009; Zaiceva and Zimmerman, 2012). Specifically, Zaiceva and Zimmerman (2012) use the EU Labour Force Survey to generate a sample of returning migrants, and based on this they analyse the return migration to the new EU Member States during the crisis. They find that the probability to return is positively correlated
} 
ferences in the data collection procedures and definitions (age of immigrants, stocks and flows of migrants), across countries exist, (see Zaiceva and Zimmerman, 2012), and no comprehensive macro-data on flows of returning migrants exist for the EU. However, there is data on emigration by country of next usual residence $^{12}$ and it can be used to shed some light on the return migration patterns. Even if this measure does not contain information on the immigrants' country of birth-citizenship nor on their previous immigration movements, it gives information on the number of individuals departing from a given host country to a particular next country of residence. Hence, it is related to the number of immigrants who arrived in the destination and then returned to their home country, giving a rough approximation of the number of return migrants. We make a simple and illustrative analysis by considering emigration from the old EU countries to other EU countries in $2009^{13}$. Although there are differences, the old EU countries have on average relative generous welfare arrangements compared to the potential destination countries, and we may therefore find indications of how welfare generosity affect return migration. We find a negative and significant correlation between the emigration rate and the benefit generosity of the host country, where the welfare state generosity in the host country is proxied by the unemployment benefit net replacement rates ${ }^{14}$. The negative coefficient of the unemployment benefit replacement rate remains significant after introducing various controls, including earnings differences between the home and the host countries (see Table 1). This suggests that higher benefit generosity in the host country is associated with lower emigration rates among previous immigrants ${ }^{15}$.

The data problem implies that there are few studies on the role of welfare generosity for return migration. One study for the US by Reagan and Olsen (2000) find that welfare benefit generosity does not affect the return probability, but the welfare programme participation negatively impacts on the immigrants' probability to return. Empirical evidence on the effect of unemployment on

with the immigrants' inactivity (measured one year before the return migration). Moreover, they find no impact of unemployment status (measured one year before the return) on the probability to return.

${ }^{12}$ The emigration by country of next usual residence (source Eurostat, LFS) is defined as the "Emigration flow out of the reporting country during the reference year by country of next residence of migrants".

${ }^{13}$ We build the bilateral emigration rates as the ratio of the emigration by country of next usual residence and the population in the host country. As host countries we use the EU15 Member States, Norway and Switzerland included, Ireland and Luxembourg excluded. The countries of "next usual residence" (i.e.the home countries) include the EU28 Members States, Norway and Switzerland included, Croatia, Cyprus, Ireland, Luxembourg and Malta excluded.

${ }^{14}$ The source of the variable net replacement rate is the "Tax and benefits indicators" database, European Commission.

${ }^{15}$ We also perform the following illustrative exercise where we split the sample in two groups of host countries. One set of countries with a less generous welfare state (i.e. with net replacement rate lower than 55\%), while the other one with a generous welfare state (i.e. with net replacement rate higher than $55 \%$ ). Interestingly, we observe that the coefficient of benefit_host remains negative and significant only for the sub-sample of the "low welfare state" host countries in all the specifications. This suggests the presence of an asymmetry between host countries possibly due to different welfare state generosity. 
the immigrants' duration of stay in the destination country exists for Germany. Indeed, Kirdar (2009) finds that the effect of immigrants' unemployment on the return migration varies according to the length of the unemployment spell. Specifically, the longer the unemployment spell, the more likely the immigrant is to remain in the Germany. On the contrary, short-term unemployed immigrants tend to return migrate. An interesting recent study for Norway by Bratsberg et al. (2014) finds that the financial crisis disproportionally affected migrant workers. Although a negative labour market shock increased return migration, the majority of labour migrants remained in Norway claiming unemployment benefits ${ }^{16}$.

Even if the measure used above is a coarse proxy for return migration flows, the data indicates the existence of a negative relationship between the "exits" from a given country and its welfare state generosity. This suggests that the unemployment benefit generosity may be linked to the immigrants' return migration decision, and this motivates the theoretical analysis in the next section.

Table 1: OLS regressions of the benefit generosity in the host country on the emigration rate from the host to the next country of residence.

Dependent variable: Emigration_host_home

\begin{tabular}{llllll}
\hline & $(1)$ & $(2)$ & $(3)$ & $(4)$ & $(5)$ \\
benefit_host & $-0.027^{* *}$ & $-0.043^{* *}$ & -0.027 & $-0.028^{*}$ & $-0.031^{*}$ \\
& $(0.013)$ & $(0.021)$ & $(0.018)$ & $(0.016)$ & $(0.018)$ \\
\hline controls: & & & & \\
earning_host & no & no & no & yes & yes \\
earning_home & no & no & no & yes & yes \\
host dummies & no & yes & yes & no & yes \\
home dummies & no & no & yes & no & no \\
$R^{\wedge} 2$ & 0.021 & 0.086 & 0.423 & 0.062 & 0.125 \\
Obs & 148 & 148 & 148 & 148 & 148 \\
\hline $\begin{array}{l}\text { Notes: Emigration_host_home is the emigration rate from the host to the home country. } \\
\text { benefit_host is the unemployment benefit replacement rate in the host country. }\end{array}$ \\
\multicolumn{5}{l}{ Standard errors clustered at the country-pair level. } \\
\hline
\end{tabular}

\section{Migration, return migration and job-loss}

Our main purpose is to analyse how welfare arrangements may affect both migration and return migration and we therefore follow the literature in taking a

\footnotetext{
${ }^{16}$ Denmark constitutes another interesting case. Indeed, the percentage of immigrants from the EU receiving unemployment benefits with respect to the total number of recipients has increased from $3 \%$ in 2008 to $6 \%$ in 2014 (i.e. from 1430 EU immigrants recipients over 53300 total recipients in 2008 to 6120 over 105500 in 2014. See Dagpengekommissionens, 2015).
} 
single country perspective ${ }^{17}$. What are the drivers attracting migrant workers, and will they stay or leave in case of unemployment? We thus take a small open economy perspective by assuming an exogenous outside world, and the analysis is in this sense partial to focus on the essential mechanisms ${ }^{18}$.

The issue at hand involves migration, job-loss and return migration and for this purpose a three-period model is sufficient. In the first period a decision is made whether to migrate from Home $(h)$ to Foreign for a (better paid) job. In the second period the migrant works, and in period three the job may be lost, and a decision is made whether to stay or return to the home country. We first work out the basic insights in the most simple version of this framework. We show how to characterize the migration flows and their dependence on welfare generosity. Most importantly, we characterize two migration regimes as well as the different mechanisms underlying migration and return migration. Although some technical steps are involved, the intuition of the results turns out to be straightforward. Having settled the basics, we next show that the findings are robust to a number of modifications and extensions of the simple framework. We discuss the extensions in Section 4, while the specific analyses of the various generalizations are given in the Appendix.

Individuals differ in their migration costs which include both the direct costs of migrating and the indirect costs of shifting community in terms of loss of contact to family, friends as well as cultural and language differences etc. In the model set-up migration costs are interpreted as a monetary $\operatorname{cost}^{19}$, and the costs are symmetric with respect to migration and return migration. Individuals can be of different types $i \in I$ depending on their migration $\operatorname{costs} c_{i} \in[\underline{c}, \bar{c}]$. The distribution across types and thus migration costs is given by the density function $f(c)$, where $f(c) \geq 0$ for $c \in[\underline{c}, \bar{c}]$ and $\int_{\underline{c}}^{\bar{c}} f(c)=1$. Below we assume a uniform density function for analytical convenience.

Assume for simplicity (for generalizations see Section 4) that the migrant has a job-offer at Foreign before deciding whether to migrate. The job is maintained with probability $p$ and thus lost with probability $1-p$. Unemployed in Foreign are entitled to an unemployment benefit or social assistance $b^{20}$. If the individual decides not to migrate the expected life-time utility is given $\operatorname{as}^{21}$

\footnotetext{
${ }^{17}$ See e.g. Borjas (1987), Dustmann (2003) for an example, and Dustmann and Gorlach (2016) for a review.

${ }^{18}$ A global model would obviously be more complicated, but we develop an example in the Appendix to show that the main finding of asymmetries and persistence of migration flows remain relevant in such a setting.

${ }^{19}$ Alternatively the utility in Foreign for a migrant may be denoted $F_{i}(w)$, where $F_{i}(w)<$ $U(w)$, capturing that the utility value of income/consumption depends on the environment (family, network etc.). There exists a cost $c_{i}$ such that $F_{i}(w)=U\left(w-c_{i}\right)$ and hence the interpretation that the cost may include both explicit and implicit costs of migrating.

${ }^{20}$ Observe that we do not define the unemployment benefit-social assistance for the Home country. Indeed, we implicitly assume that the wage in Home $\left(w^{h}\right)$ already incorporates any form of welfare transfer scheme. As common in most EU countries, by working immigrants obtain eligibility to the unemployment benefit in Foreign.

${ }^{21}$ The essential assumption is that utility at home is exogenous. We model it in terms of a given wage $w^{h}$, but leaves it open whether this is market income, social transfers or the value of home production.
} 


$$
V^{h}=U\left(w^{h}\right)+\frac{1}{1+\delta} U\left(w^{h}\right),
$$

where the utility function $U()$ defined over disposable income/consumption $\left(w^{h}\right)$ satisfies standard assumptions including $U^{\prime}>0, U^{\prime \prime}<0$, and $\delta(>0)$ is the subjective discount rate. To focus on the role of unemployment and return migration we disregard savings/borrowing and assume that individuals are "hand-to-mouth" consumers. If the individual migrates to work in Foreign at the wage $w\left(w>w^{h}\right)^{22}$, the expected life-time utility is

$$
V=U\left(w-c_{i}\right)+\frac{1}{1+\delta}\left[p U(w)+(1-p) \max \left\{U(b), U\left(w^{h}-c_{i}\right)\right\}\right] .
$$

The last term reflects that the individual decides whether to stay or return in the case of job-loss. To economize on notation there is no explicit indexing of Foreign $(f)$.

\section{Migration decisions}

Proceeding in the standard way of backward induction we consider first the decision pertaining to the last period; should the migrant stay or return in case of unemployment. An unemployed migrant returns to Home if

$$
U(b) \leq U\left(w^{h}-c_{i}\right)
$$

and vice versa. Define the critical cost level $\widehat{c}(b)$ such that

$$
U(b)=U\left(w^{h}-\widehat{c}(b)\right) .
$$

Hence, $\widehat{c}(b)=w^{h}-b$, i.e. $\widehat{c}(b)$ is the critical cost level that makes the unemployed migrant indifferent between returning and staying in the second period. A migrant $i$ returns (stays) if $c_{i} \leq \widehat{c}(b)\left(c_{i}>\widehat{c}(b)\right)$. The critical cost level $\widehat{c}(b)$ is decreasing in $b$. Having determined the "to stay or return" decision if a migrant becomes unemployed, we can turn to the migration decision, would anybody migrate in the first place? Since the migration decision depends on what happens if the migrant becomes unemployed, we have to distinguish between two cases depending on whether $c_{i} \lesseqgtr \widehat{c}(b)$. Consider first individuals $i$ for whom $c_{i}>\widehat{c}(b)$, i.e. there is no return migration in case of unemployment. For this case define $c_{a}(b, p)$ as the cost level implying that

$$
U\left(w^{h}\right)+\frac{1}{1+\delta} U\left(w^{h}\right)=U\left(w-c_{a}(b, p)\right)+\frac{1}{1+\delta}[p U(w)+(1-p) U(b)],
$$

i.e. the individual $i$ is indifferent between staying at home and migrating if $c_{i}=c_{a}(b, p)$. Hence, if $c_{i} \leq c_{a}(b, p)$ the individual migrates, and vice versa for $c_{i}>c_{a}(b, p)$. The critical cost level $c_{a}(b, p)$ is increasing in both $b$ and $p$.

\footnotetext{
${ }^{22}$ Wages are defined net of taxes and social security contributions. The assumption that the wage at Foreign is higher than at Home is trivial, if the opposite, there would be no reason to consider migration.
} 
Turning to individuals $i$ where $c_{i} \leq \widehat{c}(b)$, i.e. they will return if becoming unemployed. Define $c_{b}(p)$ as the cost level such that

$U\left(w^{h}\right)+\frac{1}{1+\delta} U\left(w^{h}\right)=U\left(w-c_{b}(p)\right)+\frac{1}{1+\delta}\left[p U(w)+(1-p) U\left(w^{h}-c_{b}(p)\right)\right]$

i.e. the individual $i$ is indifferent between staying at home and migrating if $c_{i}=c_{b}(p)$. Hence, if $c_{i} \leq c_{b}(p)$ the individual migrates, and vice versa for $c_{i}>$ $c_{b}(p)$. Note that the critical cost level depends on the employment probability in the second period $p$ only (and is increasing in $p$ ) since the individual returns to home if becoming unemployed ${ }^{23}$.

To proceed we need to note that ${ }^{24}$

$$
c_{a}(b, p) \gtreqless c_{b}(p) \text { for } \widehat{c}(b) \lesseqgtr c_{b}(p) .
$$

This relation is very helpful in delimiting migration regimes. Suppose that $c_{b}(p)<\widehat{c}(b)$ then it follows that $c_{a}(b, p)<c_{b}(p)<\widehat{c}(b)$ but the critical cost level $c_{a}(b, p)$ is only defined for $c_{i}>\widehat{c}(b)$ and hence this becomes irrelevant, and only $c_{b}(p)$ becomes relevant for the migration decision. Similar reasoning holds for $c_{b}(p)>\widehat{c}(b)$ in which case only $c_{a}(b, p)$ is relevant for the migration decision.

Consider next the locus in $(b, p)$-space where

$$
c_{b}(p)=\widehat{c}(b) .
$$

Since $c_{b}(p)$ is increasing in $p$ and $\widehat{c}(b)$ is decreasing in $b$, the locus is downward sloping as illustrated in Figure 1.

We are now able to characterize the two migration regimes illustrated in Figure 1. In regime I there is complete return migration since all migrants return home if losing their job, while in regime II there is incomplete return migration since some migrants remain even if they lose their job. More precisely the two regimes are defined as follows.

Regime I- complete return migration $\widehat{c}(b) \geq c_{b}(p)$ : Since $c_{a}(b, p) \leq c_{b}(p)$, cf. (5) the migration decision is determined by $c_{b}(p)$. Individuals with $c_{i} \leq c_{b}(p)$ migrate and return if they become unemployed since $c_{b}(p) \leq \widehat{c}(b)$. Individuals $i$ with $c_{i}>\widehat{c}(b)$ do not migrate.

Regime II- incomplete return migration $\widehat{c}(b)<c_{b}(p)$ : Since $c_{a}(b, p)>$ $c_{b}(b)$, cf. (5) the migration decision is determined by $c_{a}(b, p)$. Individuals $\mathrm{i}$

\footnotetext{
${ }^{23}$ Observe that as long as $w>w^{h}>0$, migration from Home to Foreign always occurs and migration flows are finite. Indeed, given the assumption on the individual costs and on their distribution, it cannot be that all $c_{i}$ are lower than $c_{a}(b, p)$ and/or $c_{b}(p)$. This could happen only in the extreme case where $c_{a}(b, p) \geqslant \bar{c}$ and $c_{b}(p) \geqslant \bar{c}$.

${ }^{24}$ This follows from (3) and (4) implying

$$
U\left(w-c_{a}(b, p)\right)-U\left(w-c_{b}(b)\right)=\frac{(1-p)}{(1+\delta)}\left[U\left(w^{h}-c_{b}(p)\right)-U(b)\right]
$$

where it has been used that $U(b)=U\left(w^{h}-\widehat{c}(b)\right)$. Suppose that $c_{b}(p)>\widehat{c}(b)$, then the RHS of the above expression is negative and thus, $c_{a}(b, p)>c_{b}(p)$, and vice versa for $c_{b}(p) \leq \widehat{c}(b)$.
} 
Figure 1: Migration regimes: job- retention probability (p) and unemployment benefits (b).

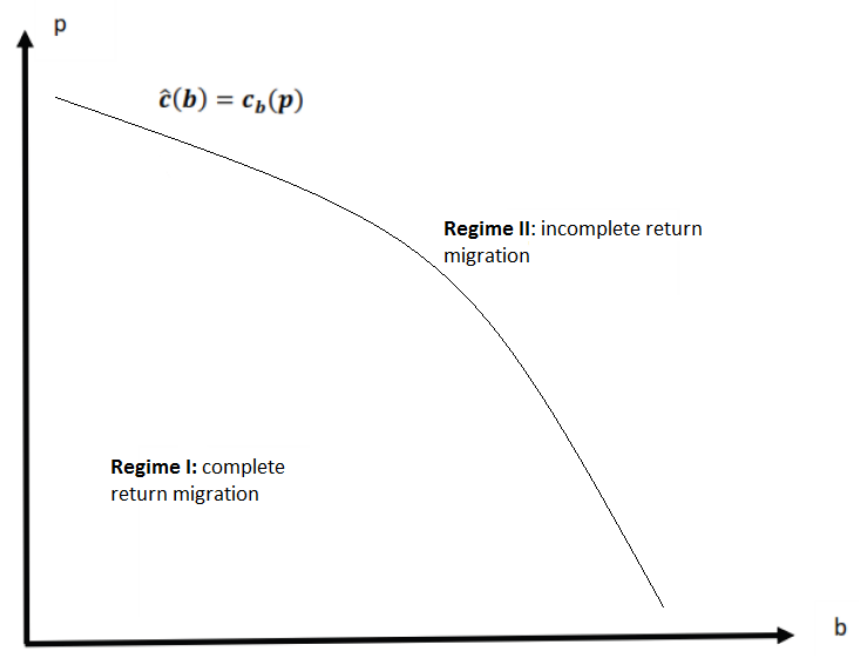

with $c_{i} \leq \widehat{c}(b)$ migrate and return if they become unemployed. Individuals with $\widehat{c}(b)<c_{i} \leq c_{a}(b, p)$ migrate and stay if they become unemployed. Individuals $i$ with $c_{i}>c_{a}(b, p)$ do not migrate.

The migration and return migration patterns for the two regimes are illustrated in Figure 2. As seen from Figure 1, which regime prevails depends on the benefit level $(b)$ relative to the probability of being in employment in the second period $(p)$. Note that regime II appears if benefit generosity is sufficiently high, for a given job retention rate $p$, and vice versa.

These results show that an important selection mechanism is at stake. Migrants are self-selected among agents with low migration costs. This is why they migrate, but that is also why they easily return if they become unemployed. If benefit generosity is low (for given $p$ ), there is migration but complete returnmigration among unemployed immigrants (regime I). Migrants do not use the social safety net. If benefit generosity is sufficiently high (for given $p$ ), the situation is more complicated (regime II). This regime has a larger inflow of migrants compared to regime I. It is still the case that the migrants with the low migration costs leave if they become unemployed $\left(c_{i} \leq \widehat{c}(b)\right)$. However, migrants with intermediary levels of migration costs $\left(\widehat{c}(b)<c_{i}<c_{a}(b, p)\right)$ stay if they become unemployed. 
Figure 2: Migration costs: migration and return migration.
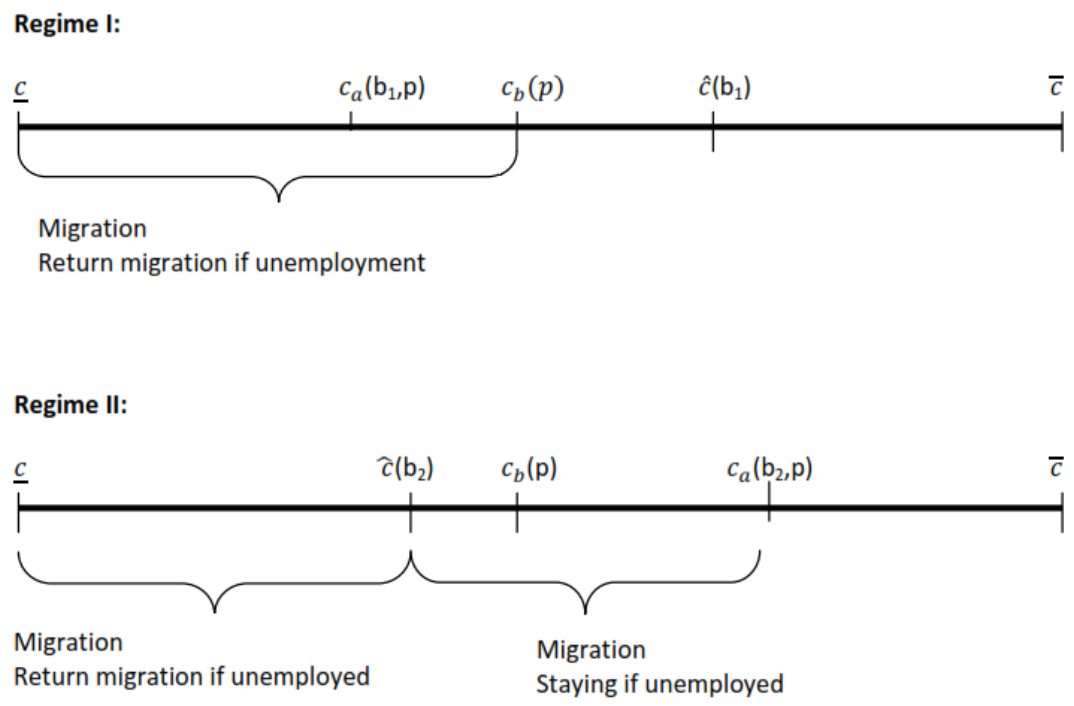

Note: the figure is drawn for given job-retention probability $p$, and two different benefit levels $b_{1}<b_{2}$ such that regime I applies for the lower benefit level and regime II for the higher benefit level.

\subsection{Determinants of migration and return migration}

The key finding is the presence of different migration regimes depending on the benefit level and the job-retention probability. In this section we explore in more detail these two regimes and how migration flows are determined within each of them. Note first that the number of migrants $\left(m^{j}\right)$, the number of migrants staying $\left(s^{j}\right)$ if they become unemployed, and those returning to home in case of unemployment $\left(r^{j}\right)$ as they depend on the migration regime $(j=I, I I)$ are related via the identity $s^{j}+r^{j}=(1-p) m^{j}$, i.e. migrants becoming unemployed either stay or return. In migration regime I the number of migrants is

$$
m^{I}(p)=\int_{\underline{c}}^{c_{b}(p)} f(c) d c=\frac{c_{b}(p)-\underline{c}}{\bar{c}-\underline{c}} .
$$

It follows straightforwardly that a marginal change in the benefit level ${ }^{25}$ does not affect the number of migrants $\left(\frac{\partial m^{I}(p)}{\partial b}=0\right)$ since all migrants who become unemployed return home $\left(r^{I}=(1-p) m^{I}\right.$ and $\left.s^{I}=0\right)$. An increase in the job-retention probability $(p)$ induces more migration

$$
\frac{\partial m^{I}(p)}{\partial p}=\frac{1}{\bar{c}-\underline{c}} \frac{\partial c_{b}(p)}{\partial p}>0
$$

${ }^{25}$ The results are under the proviso that the changes in $b$ and $p$ do not release a regime shift. 
Turning to the more interesting regime II we have that the number of migrants is given as

$$
m^{I I}(b, p)=\int_{\underline{c}}^{c_{a}(b, p)} f(c) d c=\frac{c_{a}(b, p)-\underline{c}}{\bar{c}-\underline{c}}
$$

and the number of migrants staying in case of unemployment is ${ }^{26}$

$$
s^{I I}(b, p)=(1-p) \int_{\widehat{c}(b)}^{c_{a}(b, p)} f(c) d c=(1-p) \frac{c_{a}(b, p)-\widehat{c}(b)}{\bar{c}-\underline{c}} .
$$

It follows straightforwardly that

$$
\begin{gathered}
\frac{\partial m^{I I}(b, p)}{\partial b}=\frac{1}{\bar{c}-\underline{c}} \frac{\partial c_{a}(b, p)}{\partial b}>0, \\
\frac{\partial s^{I I}(b, p)}{\partial b}=(1-p) \frac{1}{\bar{c}-\underline{c}}\left[\frac{\partial c_{a}(b, p)}{\partial b}-\frac{\partial \widehat{c}(b)}{\partial b}\right]>0,
\end{gathered}
$$

i.e. a higher benefit level induces more immigration, but it also increases the number of migrants staying in case of unemployment. Since the higher benefit level implies migration of individuals with higher migration costs, it is to be expected that the latter effect dominates the former. This is confirmed by the fact that the elasticity of number of staying migrants $\left(s^{I I}(b, p)\right)$ w.r.t. the benefit level is larger than the elasticity of migration $\left(m^{I I}(b, p)\right)$ w.r.t. the benefit level (see Appendix).

$$
\frac{\partial s^{I I}(b, p)}{\partial b} \frac{b}{s^{I I}}>\frac{\partial m^{I I}(b, p)}{\partial b} \frac{b}{m^{I I}}>0,
$$

i.e. the number of stayers is more sensitive to the benefit level than the number of migrants. This is an interesting finding since it not only points out that the role of welfare arrangements for migrant workers cannot be assessed solely from the number of immigrants, but it also shows that the margin of return migration may be most sensitive to welfare generosity. Considering how migration flows are affected by the job-retention probability we have

$$
\frac{\partial m^{I I}(b, p)}{\partial p}=\frac{1}{\bar{c}-\underline{c}} \frac{\partial c_{a}(b, p)}{\partial p}>0
$$

i.e. a higher job-retention probability induces more immigration. The effect on the number of stayers is ambiguous, i.e.

$$
\frac{\partial s^{I I}(b, p)}{\partial p}=-\frac{c_{a}(b, p)-\widehat{c}(b)}{\bar{c}-\underline{c}}+\frac{1-p}{\bar{c}-\underline{c}} \frac{c_{a}(b, p)}{\partial p} \gtreqless 0 .
$$

${ }^{26}$ The number of returning migrants is

$$
r^{I I}(b, p)=(1-p) \int_{\underline{c}}^{\widehat{c}(b)} f(c) d c=(1-p) \frac{\widehat{\widehat{c}}(b)-\underline{c}}{\bar{c}-\underline{c}} .
$$


The reason is that although the higher job-retention probability attracts more immigrants with higher migration costs (last term) who tend to stay in case of unemployment, there are fewer unemployed (first term) for whom return migration is an issue. It can also be shown that (see Appendix)

$$
\frac{\partial s^{I I}(b, p)}{\partial p} \frac{p}{s^{I I}(b, p)} \lesseqgtr \frac{\partial m^{I I}(b, p)}{\partial p} \frac{p}{m^{I I}(b, p)} .
$$

\section{Numerical illustration}

The intuition underlying the findings can be seen more clearly by the following numerical illustrations (for details see Appendix). First, the key determinants of the migration regimes are the unemployment benefit level $(b)$ and the jobretention rate $(p)$. Figure 3 shows how the number of migrants is affected by the benefit level for a given job-retention rate. For low benefits, regime I prevails, and a marginal change in the benefit level does not affect migration (and all unemployed migrants return). For a sufficiently high benefit level, migration II prevails, and a marginal increase in the benefit level induces more migration. This shows why the effect of benefit generosity on migration may be non-linear.

Considering next how the job-retention probability $(p)$ affects migration, cf.

Figure 3: Immigrant population as a percentage of total population. $b$ varies, $p$ fixed.

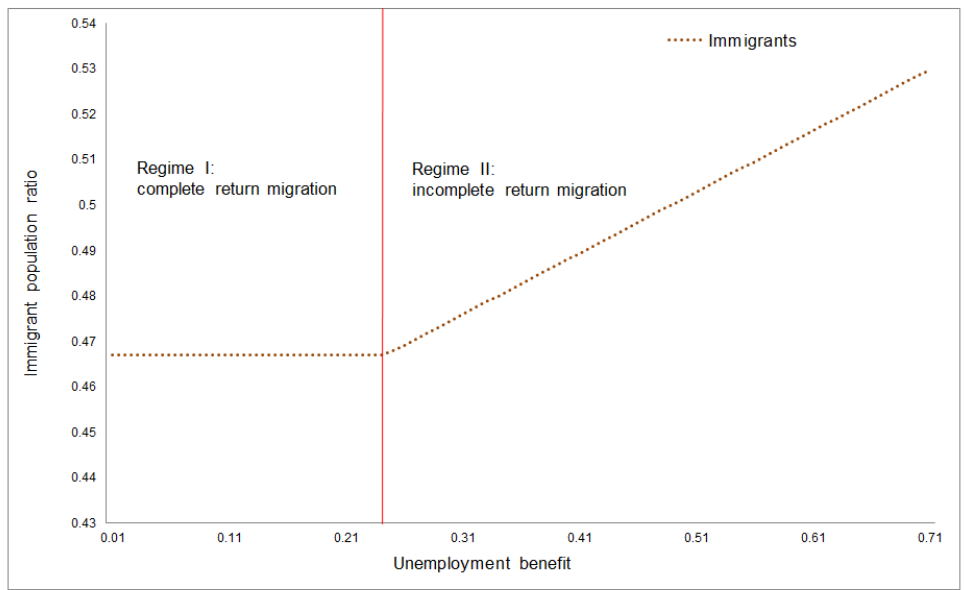

Note: detailed information about the numerical illustrations are reported in the Appendix.

Figure 4. For low job-retention rate (given $b$ ) regime I prevails, and a marginal increase in the job-retention rate induces more immigration. For a sufficiently high job-retention rate, regime II prevails and the marginal effect of an increase in the job- retention rate on migration increases. 
Figure 4: Immigrant population as a percentage of total population. $p$ varies, $b$ fixed.

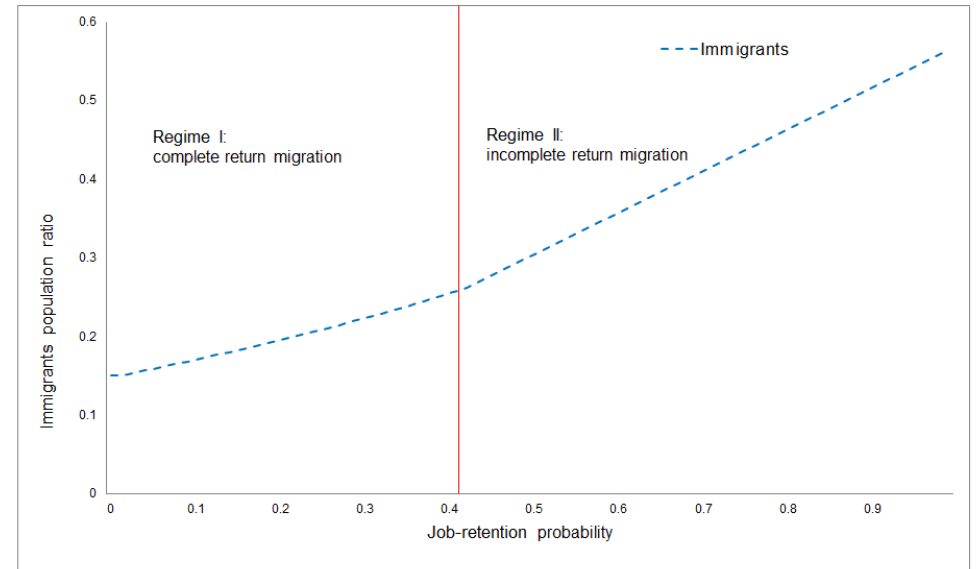

Note: detailed information about the numerical illustrations are reported in the Appendix.

Consider next return migration (or staying) in the case of unemployment. When regime I prevails, all unemployed immigrants return; when regime II appears, the rate of returnees (i.e. the ratio between unemployed returnees and immigrants) decreases in the benefit generosity (Figure 5).

The higher the job-retention rate the lower the number of returning migrants, cf. Figure 6. This holds irrespective of the regime for the obvious reason that job-loss is less frequent the higher $p$, and hence the return question arises less frequently. Moreover, passing from regime I into regime II, the number of returnees declines further. Finally, consider the number of stayers among unemployed immigrants in regime II, cf. Figure 7 and Figure 8 . In regime II, the "unemployed stayers-immigrant ratio" increases w.r.t. $b$ (Figure 7). Interestingly, this number is non-linear in the job-retention rate in regime II; the number of stayers at first increases, reaches a peak, and then declines (Figure 8). The non-linearity is driven by the fact that as the job-retention rate approaches one, there is no unemployment, and hence no issue of return migration.

\section{Extensions}

The preceding analysis worked out the basic insights in a very stylized environment. The key result is the self-selection mechanism linking the migration and return migration decision and the implied prevalence of various migration regimes, and that in regime II return migration is more sensitive to benefit 
Figure 5: Ratio between unemployed returnees and immigrants. $b$ varies, $p$ fixed.

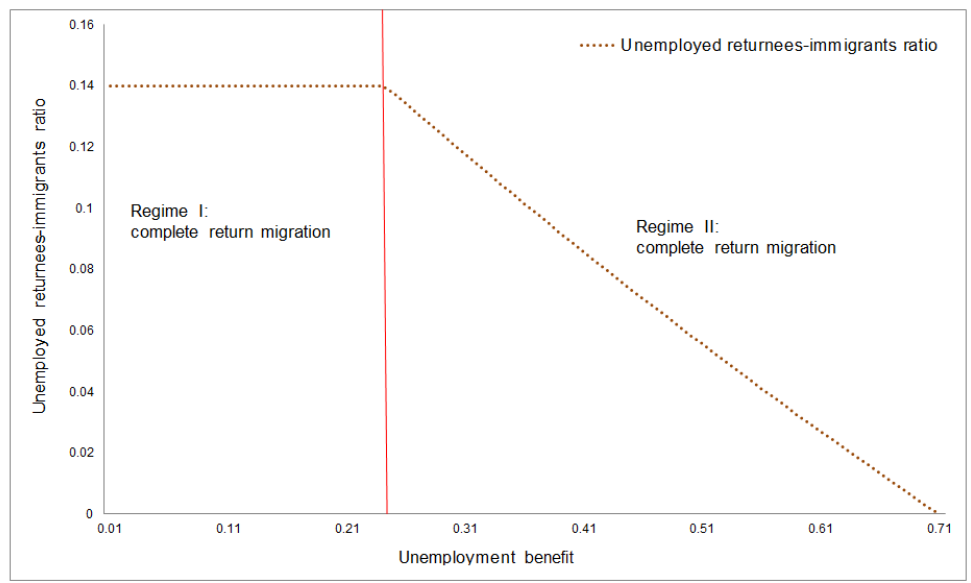

Note: in regime I all unemployed immigrants return. Hence, the ratio between unemployed returnees (i.e. $\left.(1-p) * m^{I}\right)$ and immigrants $\left(m^{I}\right)$ is equal to $(1-p)$ in regime I.

Figure 6: Ratio between unemployed returnees and immigrants. $p$ varies, $b$ fixed.

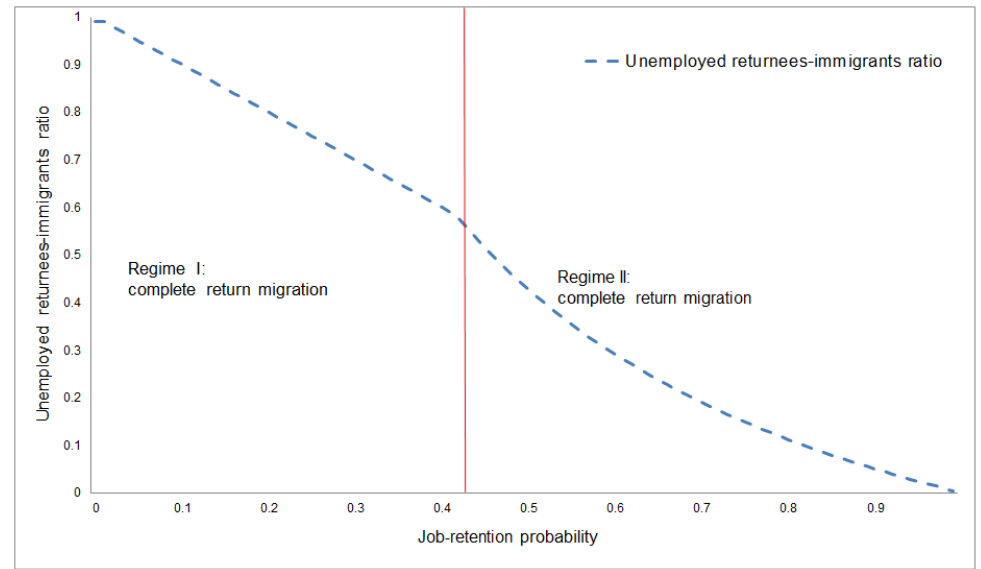

Note: detailed information about the numerical illustrations are reported in the Appendix.

generosity than the migration decision. We shall here briefly comment on the robustness of the findings to various extensions/generalization of the model (see 
Figure 7: Ratio between unemployed stayers and immigrants. $b$ varies, $p$ fixed.

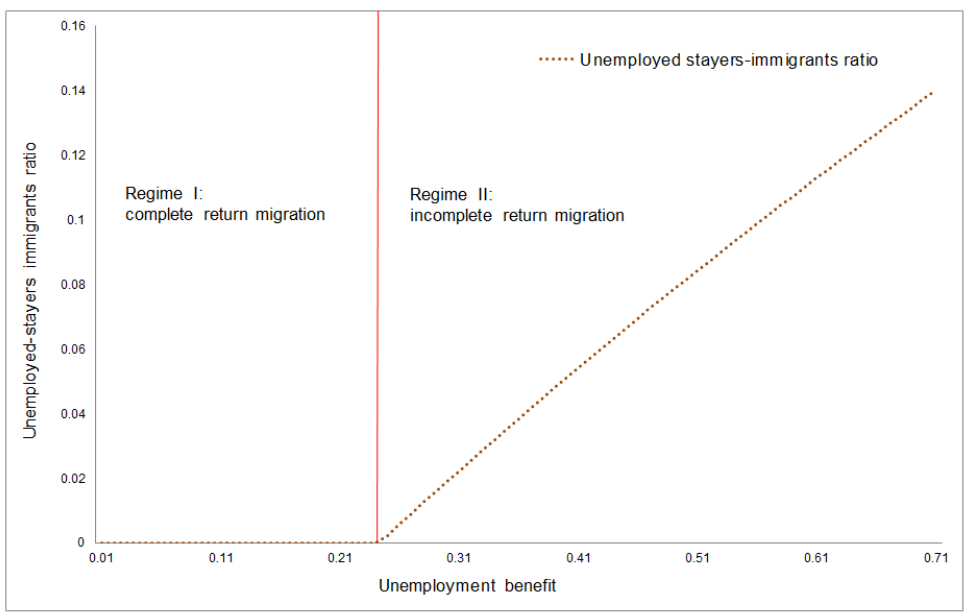

Note: detailed information about the numerical illustrations are reported in the Appendix.

Figure 8: Ratio between unemployed stayers and immigrants. $p$ varies, $b$ fixed.

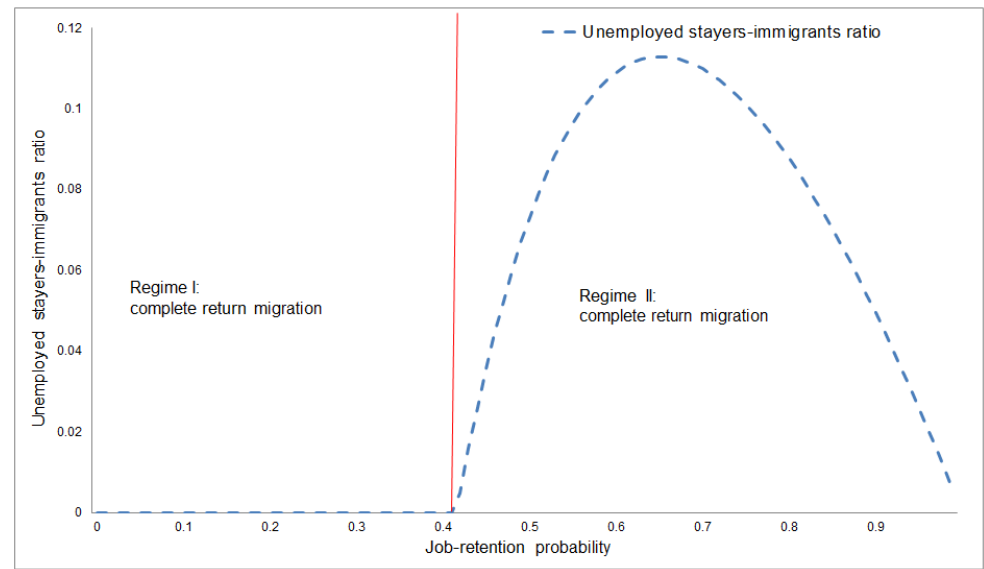

Note: detailed information about the numerical illustrations are reported in the Appendix.

Appendix for details).

It was assumed that unemployed immigrant cannot search and find a new job in Foreign. We show in the Appendix that such job-search can be allowed without changing the qualitative findings. 
For simplicity, the basic model has assumed that the alternative wage the immigrant earns in the Home country in case of return migration is equal to the wage he would have earned in both periods at Home if not migrating. However, returning immigrants may accumulate human capital when working in Foreign. In turn, this would translate into higher wages at Home in case of return. Therefore, in one of the extensions analysed the Appendix, we allow for the possibility that the wage in case of return is different from the one earned at Home if not migrating. It turns out that with a different wage in the Home country, the predictions of the basic model do not change.

The base model has assumed that migration costs are both symmetric and the same for short-term and long-term migration. It may be argued that the costs of migration are larger than those for return-migration, since the former implies a movement to a new culture, language and a loss of close contact to friends and family. In the same vein it may be argued that the costs of short-term migration are smaller than permanent migration. The main findings generalize to both of these modifications of the migration costs.

In the benchmark model, the unemployed returnee does not have the possibility to transfer the unemployment benefit to the home country. However, in the European context, unemployment benefits are portable, under certain conditions, to other EU countries. Introducing a parameter for the "degree of benefits transferability" does not change the main insights of the analysis.

The base model has assumed that job-search takes place from the home country, such that there is no unemployment risk in the first period. Job-search may be more difficult from the home country, and therefore migration may have to precede job-search. Similarly, the possibility of being in employment in the second

period may depend on period one employment. Moreover, individuals having been unemployed may find it harder to find a job. All of these aspects can be incorporated but at the costs of some complexity. However, the basic selection result stands also with these generalizations.

In the last extension, we adopt a "general equilibrium" perspective. We consider migration flows as an adjustment mechanism to a temporary wage shock. Since migration may respond asymmetrically to the wage shock (regime II), the temporary shock has a lasting implication (persistence) since a higher wage induces immigration but not a similar return-migration when the wage returns to "normal", i.e. there is path dependence in labour migration flows.

\section{Concluding remarks}

We have shown that the role of welfare generosity for migrant workers should be assessed not only in terms of immigration but also return migration. For relatively low benefit generosity, migration is unaffected by welfare generosity and all migrants return home if they become unemployed. Sufficiently high benefit levels (seen relative to the job-retention probability) generate a different migration regime which has higher migration flows, and in which job loss results in return migration for some (migrants with low migration costs) while others 
stay (migrants with intermediary migration costs). The response of migration to welfare generosity is thus non-linear since a regime change may be released. In the migration regime where some migrants stay in case of unemployment, we find that the number of stayers is more sensitive to benefit levels than the number of migrants. This suggests that return migration may be more important than migration per se in determining how the financial viability of welfare arrangements are affected by labour migration

The findings of this paper add an important dimension to the view on welfare magnet. They also point out that the empirical approach taken to clarify the presence of "welfare magnet effects" has to take account of the different migration regimes and the possible non-linear effects. Unfortunately, data on return migration is scant, but we do have some indicative evidence that welfare generosity affects return migration. The main purpose of the paper has been to point to the importance of considering both migration and return migration questions when discussion the question of welfare magnets. We have not considered the aggregate public budget effects of migration. This is an interesting next step requiring a more rich model (general equilibrium analysis) in which the labour market effects (wages, employment) of an increase in labour supply via migration should be incorporated. The importance of the job-retention probability (job finding rate) also suggests that welfare arrangements may interact with labour market institutions (e.g. employment protection legislation). It is an interesting topic for further research to pursue these questions.

Acknowledgements: We gratefully acknowledge the participants at the "Labour and Public Policy" seminar in Aarhus University, and the participants at the departmental seminar in Fern Universität Hagen for their comments. We are also thankful to Per Lundborg and Ehsan Vallizadeh for their useful suggestions. 


\section{References}

Barrett, A., Joyce, C., Maître, B., 2013. Immigrants and welfare receipt in Ireland. International Journal of Manpower 34(2), 142-154.

Barrett, A., McCarthy, Y., 2007. Immigrants in booming economy: analysing their earnings and welfare dependence. Review of Labour Economics and Industrial Relations 21(4-5), 789-808.

Borjas, J. G., 1999. Immigration and welfare magnets. Journal of Labour Economics 17(4), 607-637.

Borjas, J. G., 1987. Selection and the Earnings of Immigrants. The American Economic Review 77(4), 531-553.

Borjas, J. G., Bratsberg, B., 1994. Who Leaves? The Outmigration of the Foreign-Born. NBER Working Paper No. 4913.

Bratsberg, R., Raaum O., Røed K., 2014. Labour migrant adjustments in the aftermath of the financial crisis, IZA Discussion Paper No 8291.

Dagpengekommissionens, 2015. Dagpengekommissionens samlede anbefalinger.

De Giorgi, G., Pellizzari, M., 2013. Welfare migration in Europe. Labour Economics 16(4), 353-363.

Dustmann, C., 1997. Return migration, uncertainty and precautionary savings. Journal of Development Economics 52(2), 295-316.

Dustmann, C., 2003. Return migration, wage differentials, and the optimal migration duration. European Economic Review 47(2), 353-369.

Dustmann, C., 1999. Temporary migration, Human capital and Language fluency of migrants. Scandinavian Journal of Economics 101(2), 297-314.

Dustmann, C., Gorlach S. J., 2016. The Economics of Temporary Migrations. Journal of Economic Literature 54(1), 98-136.

EEAG, 2015. The EEAG report on the European economy, Ch. 4 Migration in the European Union, CESifo, Munich.

Hansen, J., Lofstrom, M., 2009. The dynamics of immigrant welfare and labor market behaviour. Journal of Population Economics 22(4), 941-70.

Hansen, M.F., Shcultz-Nielsen, M.L., Tranaes, T.. 2015. The impact of immigrants on public finances - a forecast analysis for Denmark, Rockwool Foun- 
dation Research Unit, Study Paper no 90.

Giulietti, C., 2014. The welfare magnet hypothesis and the welfare take-up of migrants. IZA World of Labor 37.

Giulietti, C., Guzi, M., Kahanec, M., Zimmerman, K. F., 2013. Unemployment benefits and immigration: Evidence from the EU. International Journal of Manpower 34(1), 24-38.

Kirdar, M. G., 2009. Labor Market Outcomes, Savings Accumulation, and Return Migration. Labour Economics 16(4), 418-28

Martin, R., Radu, D., 2009. Return migration: the experience of Eastern Europe. IOM International Migration.

Mayr, K., Peri, G., 2009. Brain drain and brain return: theory and application to Eastern Western Europe. The B.E. Journal of Economic Analysis and Policy, Berkley Electronic Press 9(1).

Nannestad, P., 2007. Immigration and welfare states: a survey of 15 years of research. European Journal of Political Economy 23(2), 512-532.

OECD, 2013. The fiscal impact of immigration in OECD countries, in International Migration Outlook 2013, OECD, Paris.

Pedersen, P. J., Pytlikova, M., Smith, N., 2008. Selection and network effects: migration flows into OECD countries 1990-2000. European Economic Review 52 (7), 1160-1186.

Pellizzari, M., 2013. The use of welfare by migrants in Italy. International Journal of Manpower 34(2), 155-166.

Riphahn, R.T., 2004. Immigration participation in social assistance programs. Applied Economics Quarterly 50(4), 329-62.

Razin, A., Wahba, J., 2011. Welfare magnet hypothesis, fiscal burden and immigration skill selectivity. NBER Working Paper 17515.

Reagan, P. B., Olsen, J., 2000. You can go home again: evidence from longitudinal data. Demography 37(3), 339-350.

Skupnik, C., 2014. EU enlargement and the race to the bottom of welfare states. IZA Journal of Migration 3(15).

Zaiceva, A., Zimmerman, K. F., 2012. Returning home at times of trouble? Return migration of EU enlargement migrants during the crisis. IZA DP no. 
7111.

Zimmermann, K. F., Kahanec, M., Giulietti, C., Guzi, M., Barrett, A., Bertrand,M., 2012. Study on Active Inclusion of Migrants. IZA Research Reports 43, Institute for the Study of Labor (IZA). 


\section{Appendix}

\subsection{Details on the numerical illustrations}

For the numerical illustrations reported above, we refer to the benchmark case of the model (i.e. no job risk and no asymmetric payoffs) and we use a linear utility function. In the numerical illustration, we use the following set of values (see Table 2 below): for simplicity, we scale the wage in Foreign country $(w)$ from 0 to 1 and we set $w=1$. The wage of the Home country $\left(w^{h}\right)$ is set equal to $0.71^{27}$. The probability of immigrants to keep their job in the foreign country is set equal to $0.86^{28}$ and the unemployment benefit b is set equal to 0.45. Observe that $b<0.71=w^{h}$, so the cost $\widehat{c}(b)=w^{h}-b$ is always non negative. The subjective discount rate is equal to 0.04 .

Table 2: values of the parameters.

\begin{tabular}{cc} 
& Values \\
\hline$w$ & 1 \\
$w^{h}$ & 0.71 \\
$p$ & 0.86 \\
$b$ & 0.45 \\
$\delta$ & 0.04 \\
\hline \hline
\end{tabular}

Using this set of values, we find the locus of points where $\widehat{c}(b)=c_{b}(p)$, cf. Figure 9 . As shown in Section 3 (cf. Figure 2), this locus defines the values of $b$ and $p$ delimiting the two migration regimes. For low benefit generosity seen relative to the job-retention probability, regime I (complete return migration) occurs. Generous welfare states seen relative to the job-retention probability give rise to regime II, where some unemployed immigrants return and some others stay.

It can be seen that when $b$ varies and $p=0.86$, the shift from regime I to regime II occurs for $b=0.25$ (as illustrated also in Section 3, cf. Figure 3, Figure 5 , and Figure 7). Moreover, Figure 9 shows that when $p$ varies and $b=0.45$ (as in the numerical illustrations in Figure 4, Figure 6, and Figure 8), the threshold value of $p$ delimiting regime I and regime II is 0.44 .

\footnotetext{
${ }^{27}$ The mean value in 2009 of the net earnings in the home countries (see data used in the motivating evidence) is almost $30 \%$ lower than the one in the destination (host) countries. Hence, we set $w^{h}=0.71$.

${ }^{28}$ The average unemployment rate in EU27 countries for foreign-born individuals is equal to $14 \%$ in 2009 (source: OECD International Migration Database). Hence we approximate $p$, the job-retention probability, as 1-0.14, i.e. 0.86 .
} 
Figure 9: Numerical illustration of the migration regimes. Job-retention probability $(p)$ and unemployment benefit $(b)$.

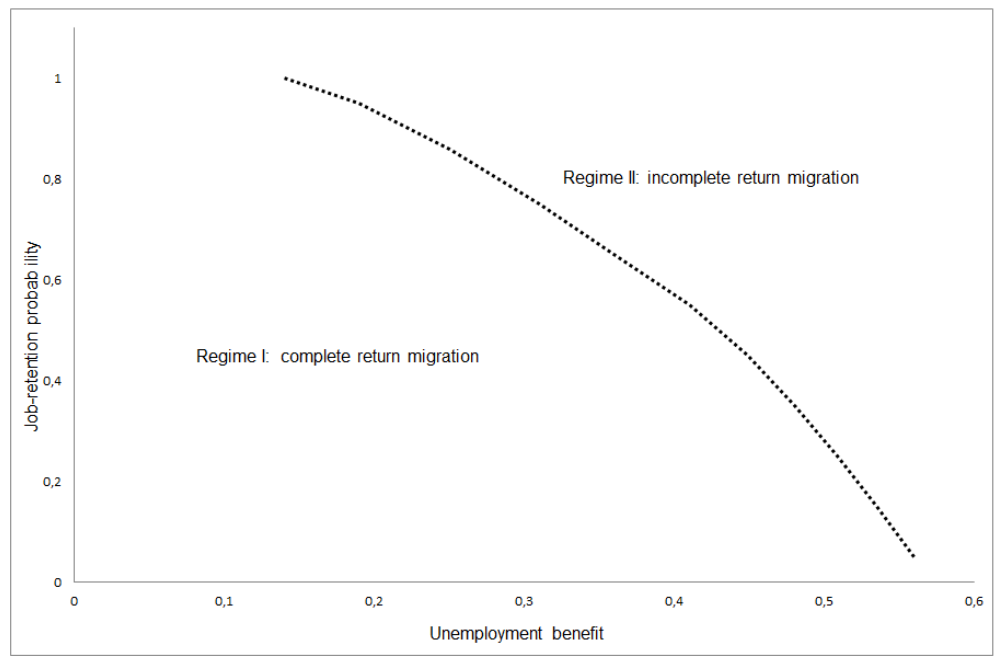

\subsection{Elasticities of migration flows}

The elasticity of migration with respect to $b$ is

$$
\begin{aligned}
\frac{\partial m^{I I}(b, p)}{\partial b} \frac{b}{m^{I I}} & =\frac{1}{\bar{c}-\underline{c}} \frac{\partial c_{a}(b, p)}{\partial b} \frac{b}{m^{I I}} \\
& =\frac{\partial c_{a}(b, p)}{\partial b} b\left[c_{a}(b, p)-\underline{c}\right]^{-1}>0
\end{aligned}
$$

and the elasticity of stayers with respect to $b$ as

$$
\begin{aligned}
\frac{\partial s^{I I}(b, p)}{\partial b} \frac{b}{s^{I I}} & =\frac{b}{s^{I I}}\left\{(1-p) \frac{1}{\bar{c}-\underline{c}}\left[\frac{\partial c_{a}(b, p)}{\partial b}-\frac{\partial \widehat{c}(b)}{\partial b}\right]\right\} \\
& =\left\{\frac{b(\bar{c}-\underline{c})}{\left(c_{a}(b)-\widehat{c}(b)\right)(1-p)}\right\}\left\{(1-p) \frac{1}{\bar{c}-\underline{c}}\left[\frac{\partial c_{a}(b, p)}{\partial b}-\frac{\partial \widehat{c}(b)}{\partial b}\right]\right\} \\
& =\left\{\frac{b}{\left(c_{a}(b, p)-\widehat{c}(b)\right)}\right\}\left[\frac{\partial c_{a}(b, p)}{\partial b}-\frac{\partial \widehat{c}(b)}{\partial b}\right] \\
& =\left\{b\left[c_{a}(b, p)-\widehat{c}(b)\right]^{-1}\right\}\left[\frac{\partial c_{a}(b, p)}{\partial b}-\frac{\partial \widehat{c}(b)}{\partial b}\right]>0 .
\end{aligned}
$$

The number of returnees in case of unemployment is

$$
r^{I I}(b, p)=(1-p) \int_{\underline{c}}^{\widehat{c}(b)} f(c) d c=(1-p) \frac{\widehat{c}(b)-\underline{c}}{\bar{c}-\underline{c}},
$$


which implies

$$
\begin{aligned}
\frac{\partial r^{I I}(b, p)}{\partial b} & =\frac{(1-p)}{\bar{c}-\underline{c}} \frac{\partial \widehat{c}(b)}{\partial b}<0 \\
\frac{\partial r^{I I}(b, p)}{\partial p} & =-\frac{\widehat{c}(b)-\underline{c}}{\bar{c}-\underline{c}}+\frac{1-p}{\bar{c}-\underline{c}}\left[\frac{\partial \widehat{c}(b)}{\partial p}\right]<0 \\
0 & <\widehat{c}(b)-\underline{c}
\end{aligned}
$$

since $\widehat{c}(b)-\underline{c}>0, \frac{\partial \widehat{c}(b)}{\partial b}<0$ and $\frac{\partial \widehat{c}(b)}{\partial p}=0$ The number of unemployed returnees is decreasing in $b$ and in $p$ : a higher benefit level and a higher jobretention probability decreases the number of unemployed returnees. The elasticity of the returnees w.r.t. $b$ is given by

$$
\frac{\partial r^{I I}(b, p)}{\partial b} \frac{b}{r^{I I}}=b \frac{\bar{c}-\underline{c}}{(\widehat{c}(b)-\underline{c})(1-p)} \frac{(1-p)}{\bar{c}-\underline{c}} \frac{\partial \widehat{c}(b)}{\partial b}=\frac{b}{(\widehat{c}(b)-\underline{c})} \frac{\partial \widehat{c}(b)}{\partial b}<0,
$$

that is always negative.

To compare the elasticities of the immigrants and of the stayers w.r.t. $b$ note that

$$
\left\{b\left[c_{a}(b)-\widehat{c}(b)\right]^{-1}\right\}\left[\frac{\partial c_{a}(b)}{\partial b}-\frac{\partial \widehat{c}(b)}{\partial b}\right]>\frac{\partial c_{a}(b, p)}{\partial b} b\left[c_{a}(b)-\underline{c}\right]^{-1}
$$

Hence,

which holds since $\left[c_{a}(b)-\underline{c}\right]>\left[c_{a}(b)-\widehat{c}(b)\right]$ and $\left[\frac{\partial c_{a}(b)}{\partial b}-\frac{\partial \widehat{c}(b)}{\partial b}\right]>\frac{\partial c_{a}(b, p)}{\partial b}$.

$$
\frac{\partial s^{I I}(b, p)}{\partial b} \frac{b}{s^{I I}}>\frac{\partial m^{I I}(b, p)}{\partial b} \frac{b}{m^{I I}}>\frac{\partial r^{I I}(b, p)}{\partial b} \frac{b}{r^{I I}} .
$$

Turning to the employment retention probability $p$ we have

$$
\frac{\partial s^{I I}(b, p)}{\partial p}=-\frac{c_{a}(b, p)-\widehat{c}(b)}{\bar{c}-\underline{c}}+\frac{1-p}{\bar{c}-\underline{c}} \frac{\partial c_{a}(b, p)}{\partial p} \gtreqless 0
$$

and hence

$$
\frac{\partial s^{I I}(b, p)}{\partial p} \frac{p}{s^{I I}(b, p)}=-\frac{p}{1-p}+\frac{\frac{\partial c_{a}(b, p)}{\partial p} p}{c_{a}(b, p)-\widehat{c}(b)} \gtreqless 0 .
$$

Moreover, since

$$
\frac{\partial m^{I I}(b, p)}{\partial p}=\frac{1}{\bar{c}-\underline{c}} \frac{\partial c_{a}(b, p)}{\partial p}
$$

we have

$$
\frac{\partial m^{I I}(b, p)}{\partial p} \frac{p}{m^{I I}(b, p)}=\frac{\frac{\partial c_{a}(b, p)}{\partial p} p}{c_{a}(b, p)-\underline{c}}>0 .
$$


It follows that

$$
\frac{\partial s^{I I}(b, p)}{\partial p} \frac{p}{s^{I I}(b, p)} \lesseqgtr \frac{\partial m^{I I}(b, p)}{\partial p} \frac{p}{m^{I I}(b, p)} .
$$

Indeed,

$$
\begin{array}{r}
-\frac{p}{1-p}+\frac{\frac{\partial c_{a}(b, p)}{\partial p} p}{c_{a}(b, p)-\widehat{c}(b)} \lesseqgtr \frac{\frac{\partial c_{a}(b, p)}{\partial p} p}{c_{a}(b, p)-\underline{c}} \\
\frac{\partial c_{a}(b, p)}{\partial p}\left[\frac{1}{c_{a}(b, p)-\widehat{c}(b)}-\frac{1}{c_{a}(b, p)-\underline{c}}\right] \lesseqgtr \frac{1}{1-p} .
\end{array}
$$

\subsection{Extensions}

The appendix contains a more detailed analysis of the extensions mentioned in the main text.

\subsection{Job search in case of stay in Foreign}

The basic model assumes that the unemployed immigrant is entitled to an unemployment benefit $b$ in case of stay in Foreign. Indeed, the aim of the model is to investigate the role of welfare arrangements on the "stay or return" migration decision of the unemployed immigrant worker. Hence, ruling out other alternatives for the immigrant in case of stay seems straightforward. However, different alternative scenarios can be incorporated in the basic framework in case of stay, without any loss of generality of the main predictions of the model. For instance, the unemployed immigrant can search/find immediately a new job in Foreign in case of stay. Specifically, it can be assumed that the individual stays and gets the benefit $b$ with probability $z$, while with probability $(1-z)$ he stays and searches/finds a new job, getting the wage of Foreign $(w)$. Hence, his expected utility in case of migration becomes

$V=U\left(w-c_{i}\right)+\frac{1}{(1+\delta)}\left[p U(w)+(1-p) \max \left[z U(b)+(1-z) U(w), U\left(w^{h}-c_{i}\right)\right]\right]$

Therefore, the expected utility of the "migration and stay" decision is

$$
\begin{aligned}
& U\left(w-c_{i}\right)+\frac{p U(w)}{(1+\delta)}+\frac{(1-p)}{(1+\delta)}[z U(b)+(1-z) U(w)] \\
& U\left(w-c_{i}\right)+\frac{p U(w)}{(1+\delta)}+\frac{(1-p) z U(b)}{(1+\delta)}+\frac{(1-p)(1-z) U(w)}{(1+\delta)} \\
& U\left(w-c_{i}\right)+\frac{U(w)[p+(1-p)(1-z)]}{(1+\delta)}+\frac{(1-p) z U(b)}{(1+\delta)} \\
& U\left(w-c_{i}\right)+\frac{U(w)[1-z+p z]}{(1+\delta)}+\frac{(z-p z) U(b)}{(1+\delta)}
\end{aligned}
$$


Let's define $\hat{p}=1-z+p z$. It follows that

$$
U\left(w-c_{i}\right)+\frac{1}{(1+\delta)}+[\hat{p} U(w)+(1-\hat{p}) U(b)]
$$

Note that this formulation is equivalent to the one in the basic model, i.e.

$$
U\left(w-c_{i}\right)+\frac{1}{(1+\delta)}+[p U(w)+(1-p) U(b)]
$$

Therefore, redefining $p$ as $\hat{p}$ does not alter the expected utility of the individual in case of "migration and stay". Allowing for other possibilities for the unemployed immigrant in case of stay leads back to the general formulation of the basic model. Hence, the main predictions of the model do not change.

\subsection{Different wage for returning immigrants}

In the basic version of the model we have assumed that the "stay or return migration" decision is based on the comparison between the unemployment benefit in the Foreign country, $b$, and the alternative option the individual can earn in the Home country, $w^{h}$. Indeed, the individual decides to return (stay) if $c_{i}<\hat{c}(b)=w^{h}-b\left(c_{i}>\hat{c}(b)\right)$. We have further assumed that the alternative option $w^{h}$ in case of return is equal to the wage the individual would have earned at Home in both periods if not migrating. In this extension we relax the latter assumption and we allow for the possibility that the wage in case of return is different from the wage in the Home country earned by individuals who do not migrate in the first place (i.e. $\left.w^{h}\right)$. For instance, returning immigrants could accumulate human capital when working in the Foreign country. Hence, they could get a higher wage when return migrating than the one they would have earned if they had not migrated. Defining the wage in case of return as $w^{\text {ret } 29}$, the expected utility becomes

$U\left(w^{h}\right)+\frac{U\left(w^{h}\right)}{1+\delta}=U\left(w-c_{i}\right)+\frac{1}{1+\delta}\left[p U(w)+(1-p) \max \left[U(b), U\left(w^{r e t}-c_{i}\right)\right]\right]$.

It follows that the expected utility in case of "migration and stay" and the threshold cost $c_{a}(b, p)$ are the same as in the base model (see equation 3 ). Instead, the expected utility deriving from the decision to "migrate and return" in now given by

$$
U\left(w-c_{i}\right)+\frac{1}{1+\delta}\left[p U(w)+(1-p) U\left(w^{r e t}-c_{i}\right)\right] .
$$

Hence, the threshold $\operatorname{cost} c_{b}(p)$ making the individual indifferent between "not migrating" and "migrating and returning" is defined as

$$
U\left(w^{h}\right)+\frac{U\left(w^{h}\right)}{1+\delta}=U\left(w-c_{b}(p)\right)+\frac{1}{1+\delta}\left[p U(w)+(1-p) U\left(w^{r e t}-c_{b}(p)\right)\right] .
$$

\footnotetext{
${ }^{29}$ Note that $w^{\text {ret }}$ can also be interpreted as the wage of a third country, different from Home. Besides the particular case of return migration to the Home country, this interpretation would allow us to generalize the model to the case of "out-migration" to a third country.
} 
The threshold cost making the immigrant indifferent between staying and returning is given by $\hat{c}(b)=w^{r e t}-b$. Proceeding as in the base model and taking the difference between $c_{a}(b, p)$ (as in equation 3) and $c_{b}(p)$ (as in 23), we get that

$$
U\left(w-c_{a}(b, p)\right)-U\left(w-c_{b}(b)\right)=\frac{(1-p)}{(1+\delta)}\left[U\left(w^{r e t}-c_{b}(p)\right)-U\left(w^{r e t}-\widehat{c}(b)\right)\right]
$$

where it has been used that $U(b)=U\left(w^{r e t}-\widehat{c}(b)\right)$. Given (24), it can be shown as in the base model that

$$
c_{a}(b, p) \gtreqless c_{b}(p) \text { for } \widehat{c}(b) \lesseqgtr c_{b}(p) .
$$

Since the inequalities among the threshold costs do not change from the base model, the same migration regimes arise. Hence, the predictions of the model continue to hold. In the numerical illustration, we fix $w^{r e t}=0.8>0.71=w^{h}$ and we use the same values for the other parameters as before (see Table 2). Note that when $p$ is fixed and $b$ varies, the shift from regime I and regime II occurs when $b=0.33$, while in the basic model it occurs when $b=0.25$, see Figure 10-Figure 12. This means that when the alternative option for returnees is higher than the wage at Home, regime I, where all unemployed immigrants return, is more likely to appear (indeed, regime I occurs for a wider range of values of the benefit).

Figure 10: Immigrant population as a percentage of total population. $w^{\text {ret }}=0.8$ and $w^{h}=0.71$. $b$ varies, $p$ fixed.

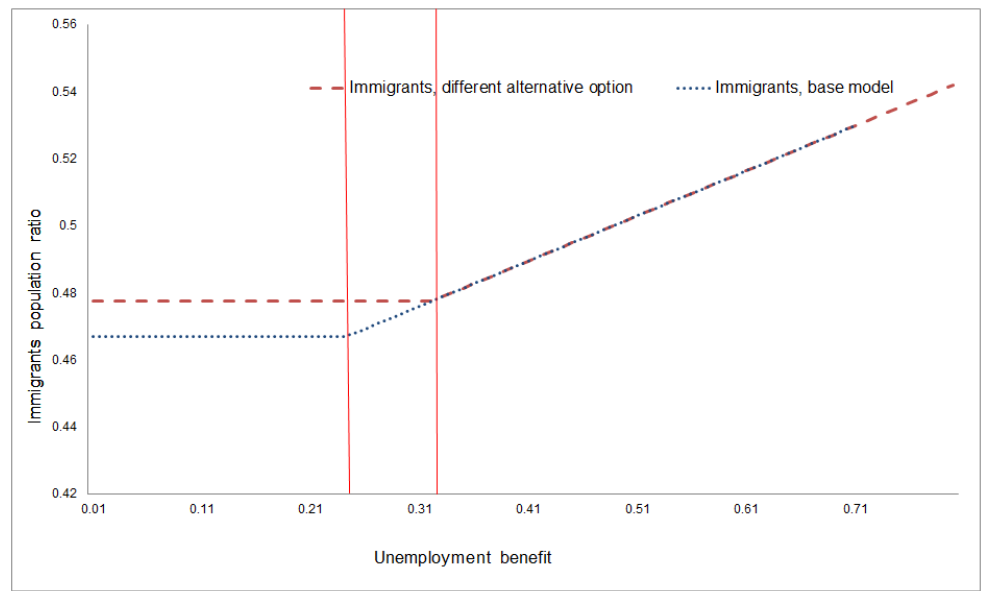


Figure 11: Ratio of unemployed stayers over immigrants. $w^{\text {ret }}=0.8$ and $w^{h}=$ 0.71 . $b$ varies, $p$ fixed.

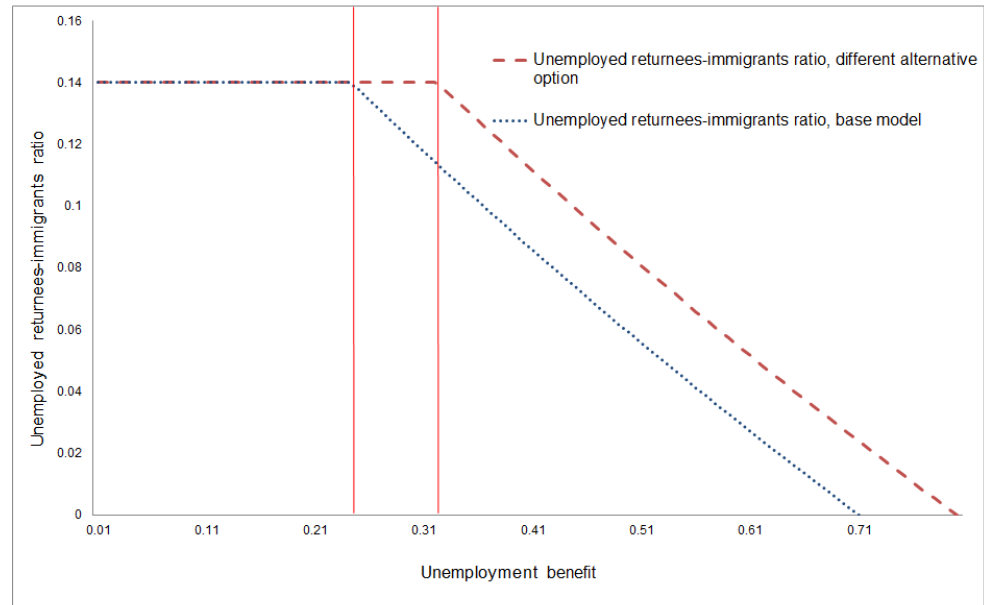

Figure 12: Ratio of unemployed stayers over immigrants. $w^{\text {ret }}=0.8$ and $w^{h}=$ $0.71 . b$ varies, $p$ fixed.

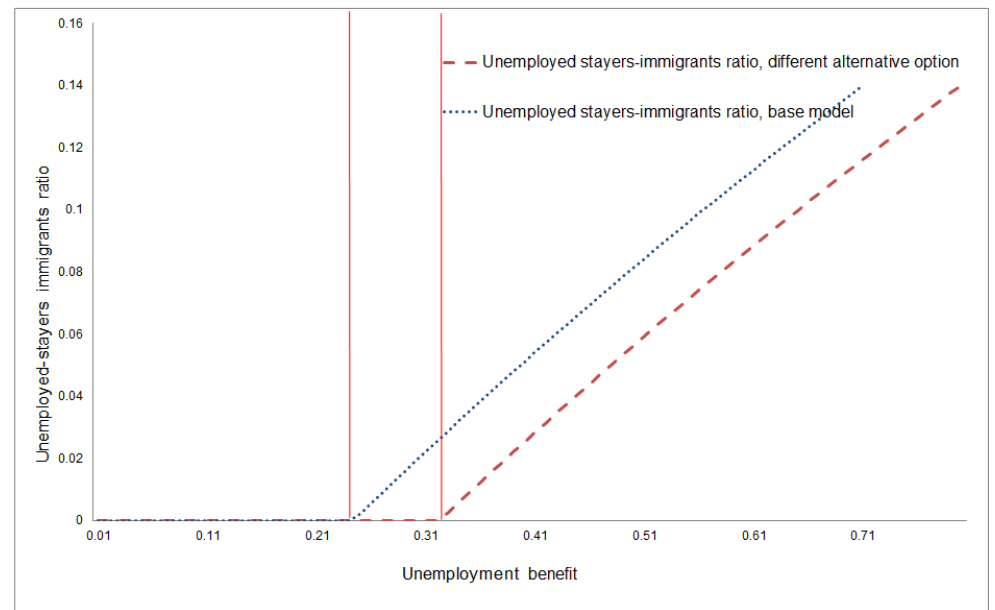

\subsection{Short-term vs long-term migration}

In the base model it was assumed that the migration costs are symmetric, i.e. a return migrant incurs the same costs when migrating as when returning to the home country. There are reasons to think that the costs differ between 
the two situations, and returning home has lower costs (the culture, language etc. is known) than migrating. Similarly, it may be argued that short-run migration has less costs than long-term migration. We modify the model here by assuming that a fraction $\lambda$ of the costs are incurred if migrating for one period, and the full costs are incurred if migrating for two. This assumption implies that a permanent migrant incurs costs $\lambda c_{i}$ the first period, and $(1-\lambda) c_{i}$ the second period. The condition determining return migration in the last period if unemployed thus reads

$$
U\left(b-(1-\lambda) c_{i}\right)=U\left(w^{h}-c_{i}\right),
$$

implying

$$
b-(1-\lambda) \widehat{c}(b)=w^{h}-\widehat{c}(b)
$$

or

$$
\widehat{c}(b, \lambda)=\frac{w^{h}-b}{\lambda}>w^{h}-b,
$$

i.e. the critical cost level becomes higher. Consider first the case with individuals $i$ for whom $c_{i}>\widehat{c}(b)$, i.e. there is no return migration in case of unemployment. For this case define $c_{a}(b, p, \lambda)$ as the cost such that

$$
\begin{aligned}
& U\left(w^{h}\right)+\frac{1}{1+\delta} U\left(w^{h}\right)=U\left(w-\lambda c_{a}(b, p, \lambda)\right)+ \\
& +\frac{1}{1+\delta}\left[p U\left(w-(1-\lambda) c_{a}(b, p, \lambda)\right)+(1-p) U\left(b-(1-\lambda) c_{a}(b, p, \lambda)\right],\right.
\end{aligned}
$$

i.e. the individual $i$ is indifferent between staying at home and migrating if $c_{i}=c_{a}(b, p, \lambda)$. Hence, if $c_{i}<c_{a}(b, p, \lambda)$ the individual migrates, and vice versa for $c_{i}>c_{a}(b, p, \lambda)$. Turning to individuals $i$ where $c_{i} \leq \widehat{c}(b, \lambda)$, i.e. they will return if becoming unemployed. Define $c_{b}(p, \lambda)$ as the cost such that

$$
\begin{aligned}
U\left(w^{h}\right)+\frac{1}{1+\delta} U\left(w^{h}\right)= & U\left(w-\lambda c_{b}(p, \lambda)\right)+ \\
& +\frac{1}{1+\delta}\left[p U\left(w-(1-\lambda) c_{b}(p, \lambda)\right)+(1-p) U\left(w^{h}-c_{b}(p, \lambda)\right)\right] .
\end{aligned}
$$

Hence, the critical cost levels change, but nothing qualitatively changes by these modifications. As in the basic model, we can show that in regime I $c_{a}(b, p, \lambda)<c_{b}(p, \lambda)<\widehat{c}(b)$ holds, while in regime II $\widehat{c}(b)<c_{b}(p, \lambda)<c_{a}(b, p, \lambda)$. Indeed, if we take the difference between $c_{a}(b, p, \lambda)$ and $c_{b}(p, \lambda)$ and assume that $c_{a}(b, p, \lambda)<c_{b}(p, \lambda)$, it follows that

$$
\begin{gathered}
(1+\delta+p)\left[U\left(w-\lambda c_{a}(b, p, \lambda)\right)-U\left(w-\lambda c_{b}(p, \lambda)\right]=\right. \\
(1-p)\left[U\left(w^{h}-c_{b}(p, \lambda)\right)-U\left(b-(1-\lambda) c_{a}(b, p, \lambda)\right]>0\right.
\end{gathered}
$$

Hence, $w^{h}-c_{b}(p, \lambda)>w^{h}-\lambda \widehat{c}(b, \lambda)-(1-\lambda) c_{a}(b, p, \lambda), \lambda \widehat{c}(b, \lambda)-c_{b}(p, \lambda)>$ $-(1-\lambda) c_{a}(b, p, \lambda)$ that is always satisfied for $\lambda \widehat{c}(b, \lambda)>c_{b}(p, \lambda)$, implying 
$\widehat{c}(b, \lambda)>c_{b}(p, \lambda)$. Hence, $c_{a}(b, p, \lambda)<c_{b}(p, \lambda) \Longleftrightarrow \widehat{c}(b, \lambda)>c_{b}(p, \lambda)$ (regime I). Instead, if $c_{a}(b, p, \lambda)>c_{b}(p, \lambda)$, then $\lambda \widehat{c}(b, \lambda)<c_{b}(p, \lambda)$. For the cost inequalities of regime II to hold, we further assume that also $\widehat{c}(b, \lambda)<c_{b}(p, \lambda)$.

We then perform the following numerical exercises. In the first one, $b$ varies and $p$ is kept fixed. In the second one, we vary $p$ and we fix $b$. Moreover, in both exercises we compare the benchmark model, which corresponds to the case with symmetric costs, i.e. $\lambda=1$, with the extension presented above with asymmetric costs, namely with $\lambda \neq 0$. Specifically, we show the exercise for $\lambda=0.7$, i.e. the case where most of the migration costs are borne in the first period or by short-term immigrants. For the other parameters, we use the same values as the ones in Table 2. In Figure 13 we observe that the immigrant population is higher (red dashed-line) than in the basic model (symmetric costs, blue dotted-line). Intuitively, lower short-term migration costs make more individuals migrating in the first period. Moreover, since the threshold cost $\widehat{c}(b, \lambda)$ is higher than $\widehat{c}(b)$, in the former case a more generous benefit is needed to induce individuals to stay in case of unemployment. The same can be observed in Figure 14 and Figure 15. Indeed, in both figures the benefit value delimiting regime I and regime II is $b=0.37$ for the asymmetric cost case and $b=0.25$ for the symmetric cost case.

Figure 13: Immigrant population as a percentage of total population when $\lambda=1$ or $\lambda=0.7$. $b$ varies, $p$ fixed.

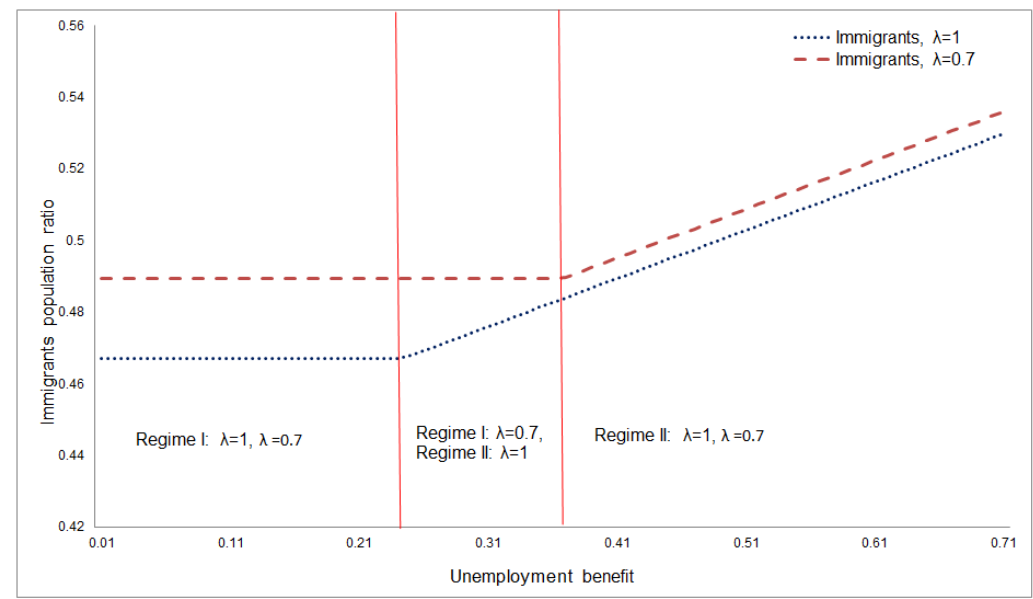

We then show the numerical exercise when $b$ is fixed and $p$ varies. In case of asymmetric costs, a higher job-retention probability increases the fraction of immigrants as in the case with symmetric costs. Moreover, in the former case, the fraction of immigrants is higher than in the latter, see Figure 16. The fraction of unemployed returnees over immigrants is decreasing with respect to 
Figure 14: Ratio of unemployed returnees over immigrants, when $\lambda=1$ or $\lambda=0.7 . b$ varies, $p$ fixed.

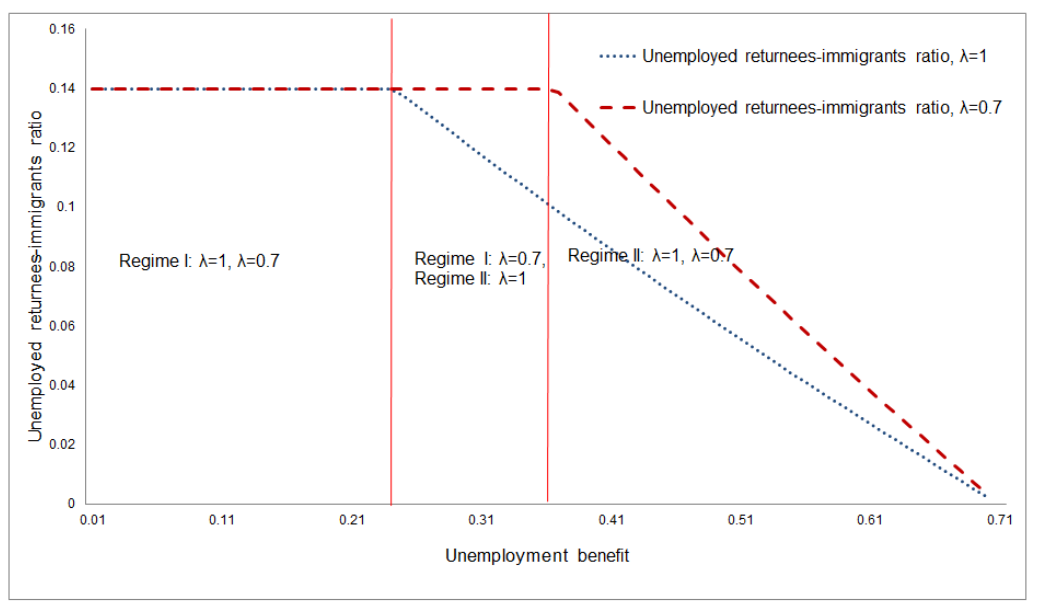

Figure 15: Ratio of unemployed stayers over immigrants, when $\lambda=1$ or $\lambda=0.7$. $b$ varies, $p$ fixed.

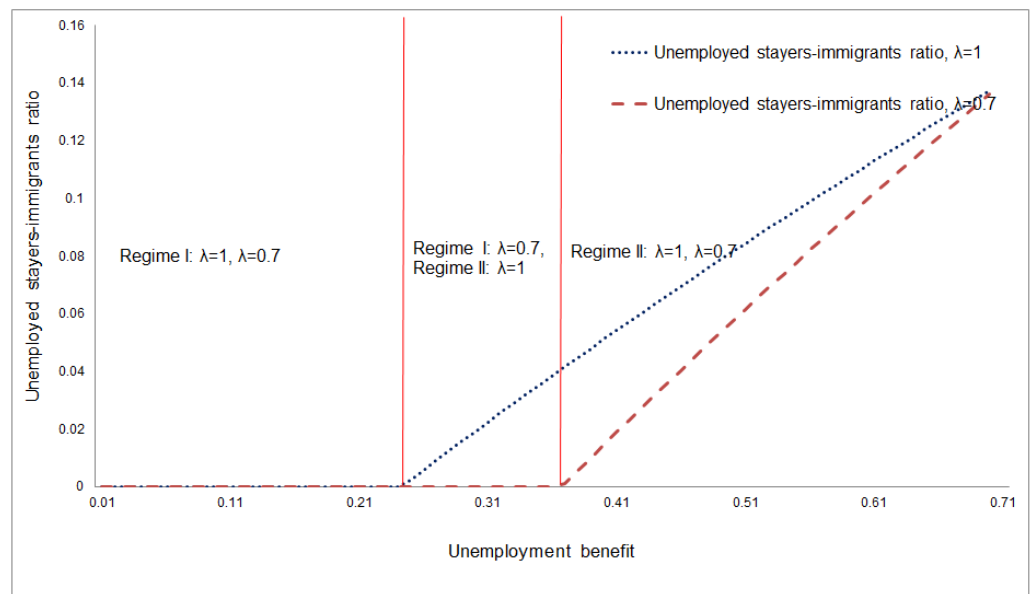

$p$ and, in regime II, it is higher than in the case with symmetric costs, Figure 17. Finally, as in the benchmark case of symmetric costs, the fraction of unemployed stayers over immigrants is non-linear in $p$ and, in regime II, it is lower than in 
Figure 16: Immigrant population as a percentage of total population when $\lambda=1$ or $\lambda=0.7 . p$ varies, $b$ fixed.

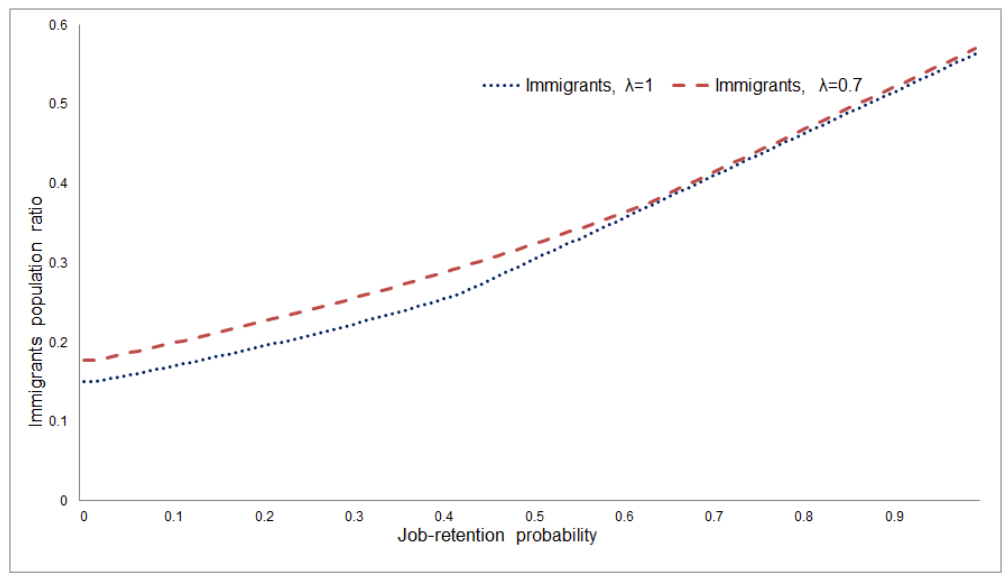

Figure 17: Ratio of unemployed returnees over immigrants, when $\lambda=1$ or $\lambda=0.7 . p$ varies, $b$ fixed.

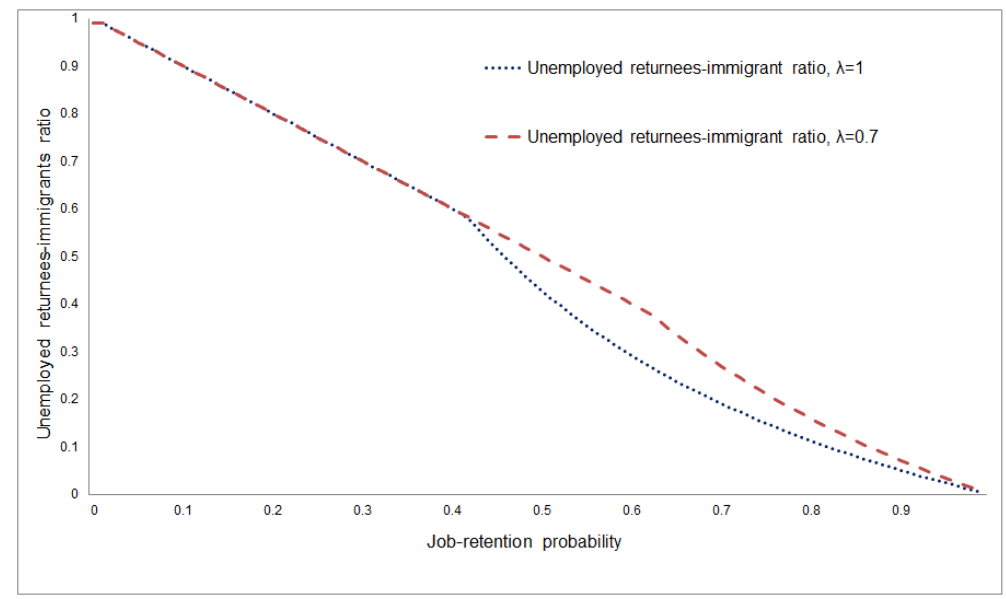

the case with symmetric costs, Figure 18. 
Figure 18: Ratio of unemployed stayers over immigrants, when $\lambda=1$ or $\lambda=0.7$. $p$ varies, $b$ fixed.

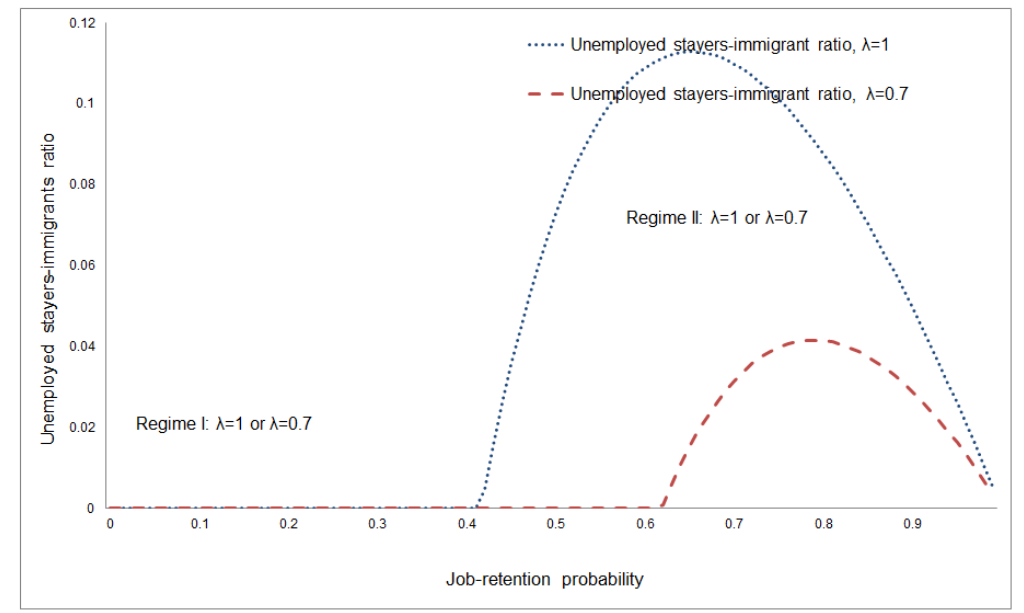

\subsection{Unemployment benefit transferability}

In the third period, the unemployed immigrant could either stay and get the unemployment benefit $b$ or he could return. If returning, he bears the individual return migration cost and he gets the home wage as in the basic case. Moreover, he is allowed to transfer a fraction $\alpha \in[0,1]$ of the unemployment benefit $b$. $\alpha$ can be interpreted as the degree of benefit transferability between countries. Specifically, in case $\alpha=0$ there is no portability (as in the benchmark case of the model), while in case $\alpha=1$ the benefit is perfectly transferable. Hence, in the third period the unemployed immigrant either stays and gets $U(b)$ or returns and gets $U\left(w_{h}+\alpha b-c_{i}\right)$. The threshold cost $\widehat{c}(b, \alpha)$ that makes him indifferent between staying and returning is now defined as

$$
\begin{aligned}
U(b) & =U\left(w^{h}+\alpha b-\widehat{c}(b, \alpha)\right) \\
b & =w^{h}+\alpha b-\widehat{c}(b, \alpha) \\
\widehat{c}(b, \alpha) & =w^{h}+(\alpha-1) b .
\end{aligned}
$$

As in the benchmark case, the cost making the individual indifferent between not migrating and migrating and stay if unemployed $c_{a}(b, p)$ is defined as

$$
U\left(w^{h}\right)+\frac{1}{1+\delta} U\left(w^{h}\right)=U\left(w-c_{a}(b, p)\right)+\frac{1}{1+\delta}[p U(w)+(1-p) U(b)] .
$$

The threshold cost making the individual indifferent between not migrating and migrating and return if unemployed is 


$$
\begin{aligned}
U\left(w^{h}\right)+\frac{1}{1+\delta} U\left(w^{h}\right)= & U\left(w-c_{b}(b, p, \alpha)\right)+ \\
& +\frac{1}{1+\delta}\left[p U(w)+(1-p) U\left(w^{h}+\alpha b-c_{b}(b, p, \alpha)\right] .\right.
\end{aligned}
$$

As in the benchmark case of the model, we have the two migration regimes depending on whether $c_{a}(b, p) \gtreqless c_{b}(b, p, \alpha) \Longleftrightarrow c_{b}(b, p, \alpha) \lesseqgtr \widehat{c}(b, \alpha)$, hence the same mechanism is still in place. Observe that from $c_{a}(b, p)-c_{b}(b, p, \alpha)$ it follows that

$$
U\left(w-c_{a}(b, p)-U\left(w-c_{b}(b, p, \alpha)\right)=\frac{1-p}{1+\delta}\left[U\left(w_{h}+\alpha b-c_{b}(b, p, \alpha)-U(b)\right] .\right.\right.
$$

Observe that differently from the benchmark model, the threshold cost $c_{b}(b, p, \alpha)$ depends now on $b$. Indeed, the return option in case of unemployment is now affected by the welfare state generosity since part of the benefit is now transferable to the Home country. This implies that the fraction of immigrants in regime $\mathrm{I}$ is $m^{I}(b, p)=\int_{c}^{c_{b}(b, p, \alpha)} f(c) d c=\frac{c_{b}(b, p, \alpha)-c}{\underline{c}-\bar{c}}$ that is increasing in $b$ since now $c_{b}(b, p, \alpha)$ is increasing w.r.t. $b$.

Suppose that $c_{a}(b, p)>c_{b}(b, p, \alpha)$. Then $U\left(w-c_{a}(b, p)-U\left(w-c_{b}(b, p, \alpha)\right)<0\right.$. Hence, $\frac{1-p}{1+\delta}\left[U\left(w^{h}+\alpha b-c_{b}(b, p, \alpha)-U(b)\right]<0\right.$, i.e. $U\left(w^{h}+\alpha b-c_{b}(b, p, \alpha)<\right.$ $U(b)$, implying that $w^{h}+\alpha b-c_{b}(b, p, \alpha)-b<0, w^{h}+\alpha b-b<c_{b}(b, p, \alpha)$. Thus, $c_{a}(b, p)>c_{b}(b, p, \alpha)$ and $c_{b}(b, p, \alpha)>\widehat{c}(b, \alpha)$, that corresponds to regime I.

We perform the same numerical illustrations as before, i.e. we look at the case where $b$ varies and $p$ is fixed and at the one where $p$ varies and $b$ is fixed. The figures below compare the benchmark model with no benefit transferability, i.e. $\alpha=0$ with the case of benefit portability, i.e. $\alpha \neq 0$. Specifically, we show the exercise for $\alpha=0.7$. For the other parameters, we use the same values as the ones in Table 2. As anticipated, observe from Figure 19 that the immigrant population in case of benefit transferability is always increasing w.r.t. $b$. Moreover, for a relatively high value of $b(b=0.64)$, regime II appears. When $b<0.64$, we have regime I, where all immigrants have the convenience to return since the benefit is now transferable to the home country. When $b>0.64$ the immigrants population for the case with benefit transferability $(\alpha=0.7)$ is equal to the one for $\alpha=0$ (i.e. with no benefit portability). Intuitively, for relatively low values of the benefit, more immigrants find the migration option attractive (since they anticipate that they can transfer the benefit). In Figure 20 and Figure 21 we also observe that $b=0.64$ is the threshold value delimiting regime I and regime II in the case of benefit transferability, while $b=0.25$ is the threshold for the benchmark model. Observe that the returnees in case of unemployment are higher when the benefit is portable, for $b>0.64$. We show the numerical illustration exercise in the when $p$ varies and $b$ is fixed. Observe that the numerical illustrations are performed with the benefit level fixed, specifically $b=0.45$. As can be inferred from the previous figures, when $b=0.45$, we are always in regime I. Hence, even if $p$ varies (see Figure 22, Figure 23, and Figure 24), regime I always occurs. 
Figure 19: Immigrant population as a percentage of total population when $\alpha=0$ or $\alpha=0.7$. $b$ varies, $p$ fixed.

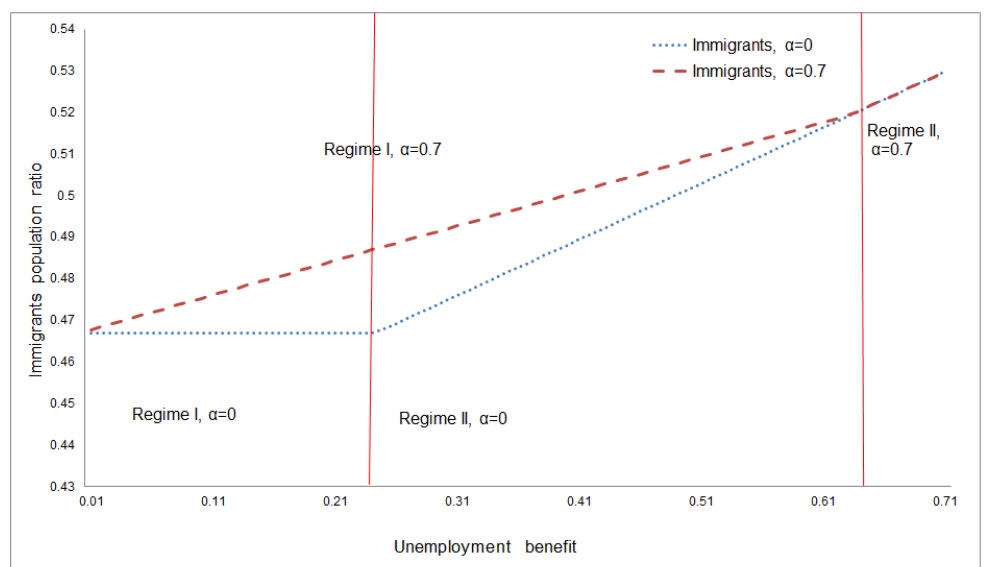

Figure 20: Ratio of unemployed returnees over immigrants, when alpha $=0$ or $\alpha=0.7$. $b$ varies, $p$ fixed.

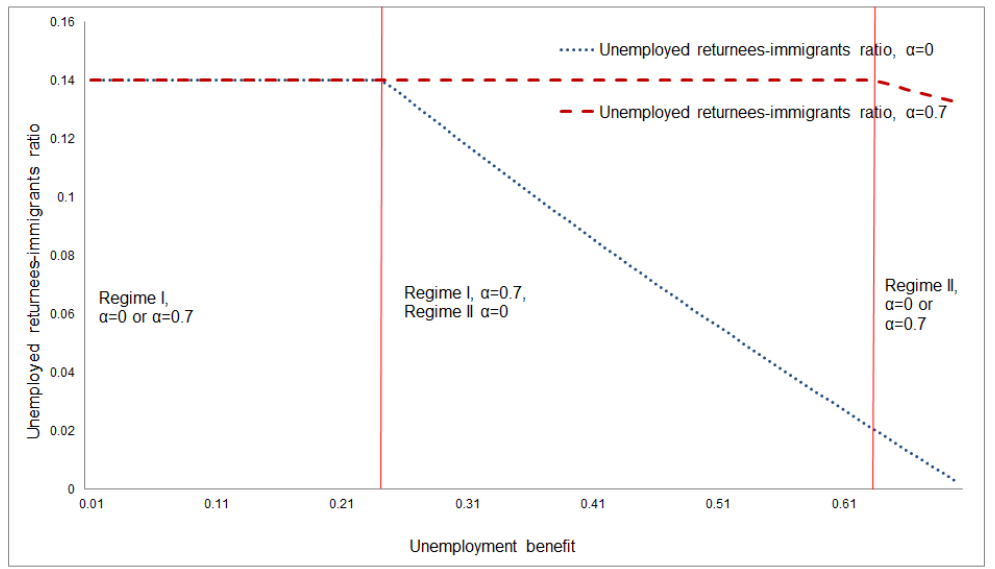


Figure 21: Ratio of unemployed stayers over immigrants, when alpha $=0$ or $\alpha=0.7 . b$ varies, $p$ fixed.

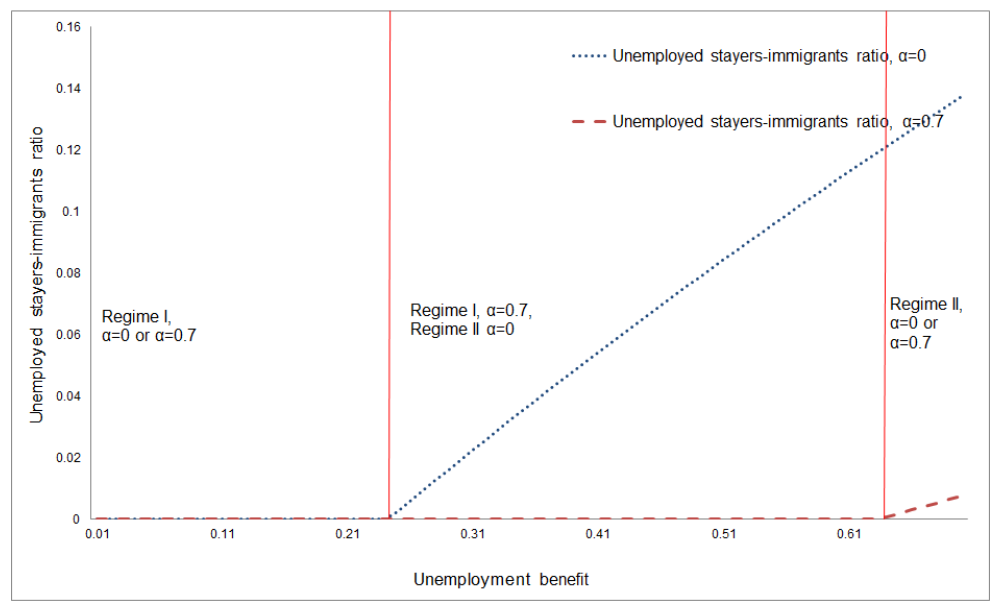

Figure 22: Immigrant population as a percentage of total population when $\alpha=0$ or $\alpha=0.7$. $p$ varies, $b$ fixed.

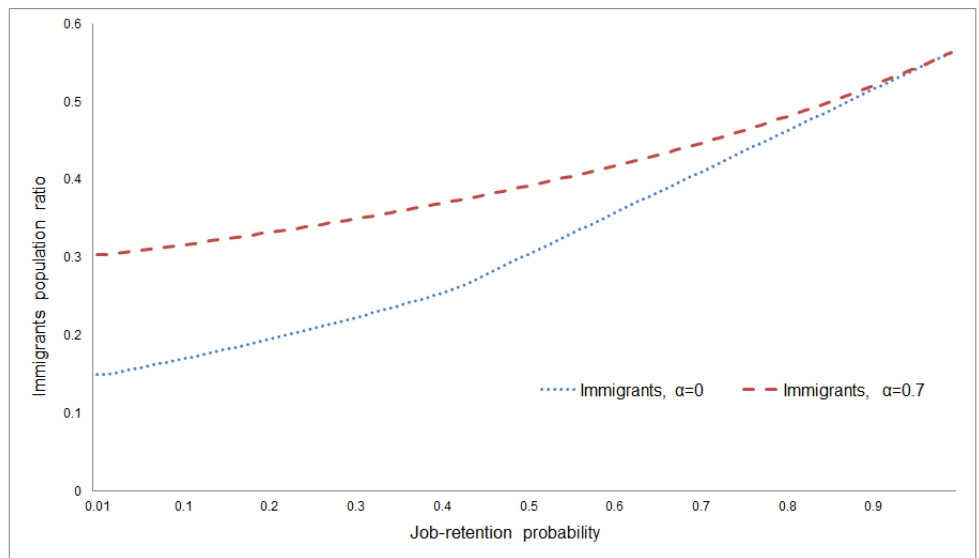


Figure 23: Ratio of unemployed returnees over immigrants, when $\alpha=0$ or $\alpha=0.7$. $p$ varies, $b$ fixed.

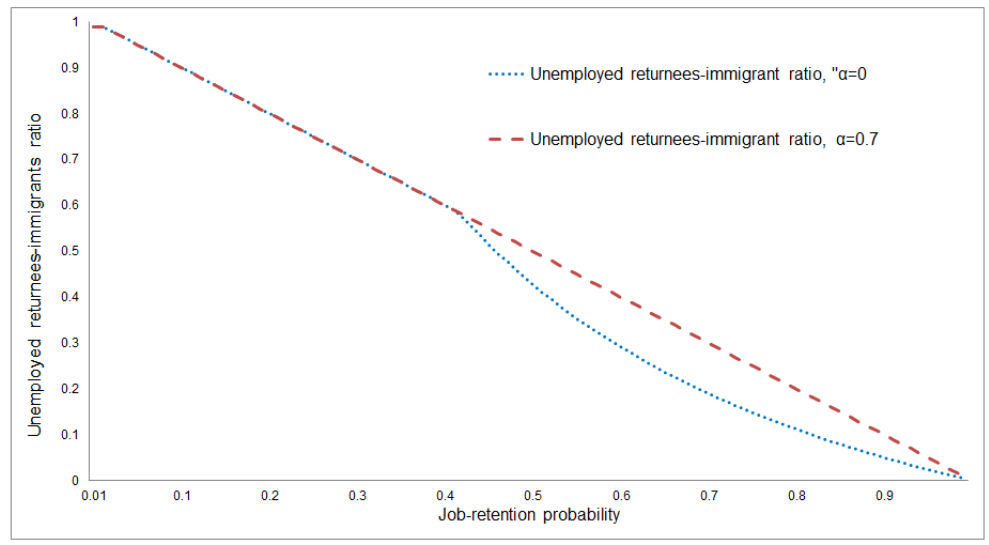

Figure 24: Ratio of unemployed stayers over immigrants, when $\alpha=0$ or $\alpha=0.7$. $p$ varies, $b$ fixed.

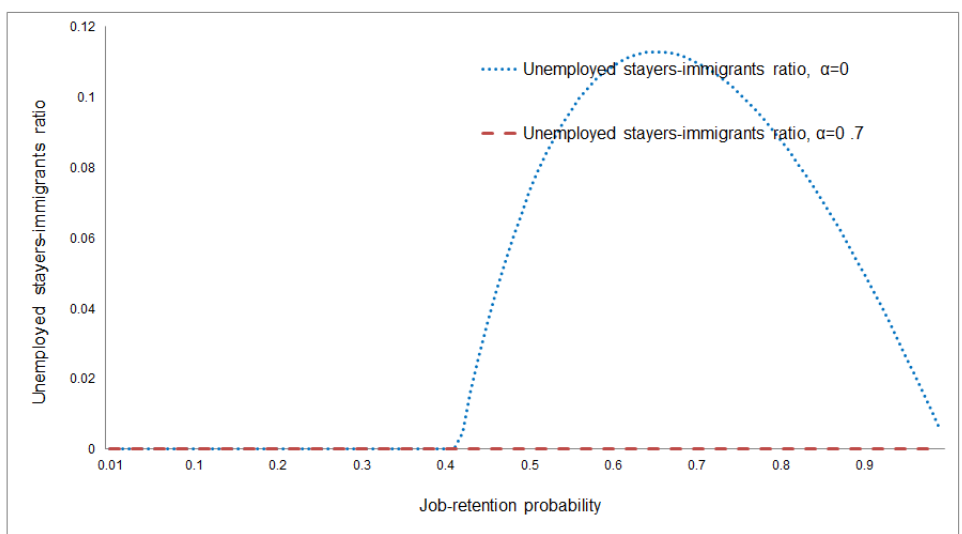

\subsection{Migration and job search}

The preceding assumed implicitly that job search is possible from the home country. Consider instead the case where job search has to take place in the labour market, i.e. migration precedes job search. Denote by $q \in(0,1)$ the 
probability that a migrant finds a job and let $p_{e}$ be the probability of retaining the job in period three. We allow for the possibility that $p_{e} \geq q$. If not employed in the first period, the employment probability is $p_{u}$ in the second period, if $p_{u}<q$ there is a discouraged worker effect. Note the sequencing assumption - we assume that the individual knows the employment state at the start of the period and can migrate/return migrate if this is advantageous ${ }^{30}$. This case is more complicated since there are now two return decisions - in period 2 if not finding a job, and similarly in period three. Note first that the expected life-time utility if migrating is

$$
\begin{aligned}
& q\left[U\left(w-c_{i}\right)+\frac{1}{1+\delta}\left[p_{e} U(w)+\left(1-p_{e}\right) \max \left\{U(b), U\left(w^{h}-c_{i}\right)\right\}\right]\right]+ \\
& +(1-q) \max \left\{\begin{array}{c}
U\left(b-c_{i}\right)+\frac{1}{1+\delta}\left[p_{u} U(w)+\left(1-p_{u}\right) \max \left\{U(b), U\left(w^{h}-c_{i}\right)\right\}\right] \\
, U\left(w^{h}-2 c_{i}\right)+\frac{1}{1+\delta} U\left(w^{h}\right)
\end{array}\right\}
\end{aligned}
$$

if not migrating life-time utility is

$$
U\left(w^{h}\right)+\frac{1}{1+\delta} U\left(w^{h}\right)
$$

The decision on return migration in period three remains

$$
U(b) \lesseqgtr U\left(w^{h}-c_{i}\right)
$$

or

$$
c_{i} \lesseqgtr \widehat{c}(b)
$$

i.e. this critical cost level is unchanged.

\subsubsection{Case $c_{i}>\widehat{c}(b)$}

We firstly consider the case $c_{i}>\widehat{c}(b)$, i.e. the case where individuals stay in period three even if unemployed, but would there be return migration in period two? This depends on

$$
U\left(b-c_{i}\right)+\frac{1}{1+\delta}\left[p_{u} U(w)+\left(1-p_{u}\right) U(b)\right] \lesseqgtr U\left(w^{h}-2 c_{i}\right)+\frac{1}{1+\delta} U\left(w^{h}\right)
$$

Define a critical cost level $c_{d}\left(b, p_{u}\right)$ by

$U\left(b-c_{d}\left(b, p_{u}\right)\right)+\frac{1}{1+\delta}\left[p_{u} U(w)+\left(1-p_{u}\right) U(b)\right]=U\left(w^{h}-2 c_{d}\left(b, p_{u}\right)\right)+\frac{1}{1+\delta} U\left(w^{h}\right)$

if $c_{i}<c_{d}\left(b, p_{u}\right)$ individual $i$ returns already in the second period, while the opposite for $c_{i}>c_{d}\left(b, p_{u}\right)$.

\footnotetext{
${ }^{30}$ Note also that, differently from before, we assume that the immigrant is eligible to the welfare benefit even if he has not worked in Foreign.
} 
We first look at the migration decision if there is no return in period two, i.e. $\widehat{c}(b)>c_{d}\left(b, p_{u}\right)$. We define the critical cost level

$$
c_{a 1}\left(b, q, p_{e}, p_{u}\right)
$$

that makes individual $i$ indifferent between migrating and not migrating in the first period, i.e.

$$
\begin{aligned}
& q\left[U\left(w-c_{a 1}\left(b, q, p_{e}, p_{u}\right)\right)+\frac{1}{1+\delta}\left[p_{e} U(w)+\left(1-p_{e}\right) U(b)\right]\right]+ \\
& +(1-q)\left[U\left(b-c_{a 1}\left(b, q, p_{e}, p_{u}\right)\right)+\frac{1}{1+\delta}\left[p_{u} U(w)+\left(1-p_{u}\right) U(b)\right]\right]= \\
& U\left(w^{h}\right)+\frac{1}{1+\delta} U\left(w^{h}\right)
\end{aligned}
$$

Suppose that there is return migration in period two (but not in period three), i.e. $\widehat{c}(b)<c_{d}\left(b, p_{u}\right)$. As before, to analyse the migration decision in period one, we define the critical cost level

$$
c_{a 2}\left(b, q, p_{e}\right)
$$

as the cost making individuals indifferent between not migrating in period one and migrating in period one, i.e.

$$
\begin{aligned}
& q\left[U\left(w-c_{a 2}\left(b, q, p_{e}\right)\right)+\frac{1}{1+\delta}\left[p_{e} U(w)+\left(1-p_{e}\right) U(b)\right]\right]+ \\
& +(1-q)\left[U\left(w^{h}-2 c_{a 2}\left(b, q, p_{e}\right)\right)+\frac{1}{1+\delta} U\left(w^{h}\right)\right]=U\left(w^{h}\right)+\frac{1}{1+\delta} U\left(w^{h}\right)
\end{aligned}
$$

Taking the difference between $c_{a 1}\left(b, q, p_{e}, p_{u}\right)$ and $c_{a 2}\left(b, q, p_{e}\right)$ and rearranging we get that

$$
\begin{aligned}
& q(1+\delta)\left[U\left(w-c_{a 1}\left(b, q, p_{e}, p_{u}\right)\right)-U\left(w-c_{a 2}\right)\right]+(1-q)(1+\delta)+ \\
& +\left[U\left(b-c_{a 1}\left(b, q, p_{e}, p_{u}\right)\right)+U\left(w^{h}-2 c_{d}\left(b, p_{u}\right)\right)-U\left(b-c_{d}\left(b, p_{u}\right)\right)-U\left(w^{h}-2 c_{a 2}\left(b, q, p_{e}\right)\right)\right]
\end{aligned}
$$

Suppose that $c_{a 1}\left(b, q, p_{e}, p_{u}\right)<c_{a 2}\left(b, q, p_{e}\right)$, i.e. that

$$
\begin{aligned}
& {\left[U\left(b-c_{a 1}\left(b, q, p_{e}, p_{u}\right)\right)+U\left(w^{h}-2 c_{d}\right)-U\left(b-c_{d}\right)-U\left(w^{h}-2 c_{a 2}\left(b, q, p_{e}\right)\right)\right] } \\
< & \frac{q}{1+q}\left[U\left(w-c_{a 2}\left(b, q, p_{e}\right)\right)-U\left(w-c_{a 1}\left(b, q, p_{e}, p_{u}\right)\right)\right]
\end{aligned}
$$

Hence, $U\left(w-c_{a 2}\left(b, q, p_{e}\right)\right)-U\left(w-c_{a 1}\left(b, q, p_{e}, p_{u}\right)\right)<0$, thus

$$
U\left(b-c_{a 1}\left(b, q, p_{e}, p_{u}\right)\right)+U\left(w^{h}-2 c_{d}\left(b, p_{u}\right)\right)-U\left(b-c_{d}\left(b, p_{u}\right)\right)-U\left(w^{h}-2 c_{a 2}\left(b, q, p_{e}\right)\right)<0
$$


Hence, from (29) and from the definition of $\widehat{c}(b)$, it can be verified that ${ }^{31}$

$$
c_{a 1}\left(b, q, p_{e}, p_{u}\right) \lesseqgtr c_{a 2}\left(b, q, p_{e}\right) \Longleftrightarrow 2 c_{a 2}\left(b, q, p_{e}\right)-c_{a 1}\left(b, q, p_{e}, p_{u}\right) \lesseqgtr c_{d}\left(b, p_{u}\right)
$$

Let's first look at the case $c_{a 1}\left(b, q, p_{e}, p_{u}\right)<c_{a 2}\left(b, q, p_{e}\right) \Longleftrightarrow 2 c_{a 2}\left(b, q, p_{e}\right)-$ $c_{a 1}\left(b, q, p_{e}\right)<c_{d}\left(b, p_{u}\right)$. Since $c_{a 1}\left(b, q, p_{e}\right)<c_{a 2}\left(b, q, p_{e}\right)$, then

$2 c_{a 2}\left(b, q, p_{e}\right)-c_{a 1}\left(b, q, p_{e}\right)>c_{a 2}\left(b, q, p_{e}\right)$. Hence, we have that

$$
\begin{aligned}
c_{a 1}\left(b, q, p_{e}\right)< & c_{a 2}\left(b, q, p_{e}\right)<2 c_{a 2}\left(b, q, p_{e}\right)-c_{a 1}\left(b, q, p_{e}\right)<c_{d}\left(b, p_{u}\right) \\
& \text { and } \\
\widehat{c}(b)< & c_{d}\left(b, p_{u}\right)
\end{aligned}
$$

Since we are now looking at the case of return in period two (i.e. $\widehat{c}(b)<$ $\left.c_{d}\left(b, p_{u}\right)\right)$, to analyse the migration decision in the first place, we need to use $c_{a 2}\left(b, q, p_{e}\right)$ as the benchmark cost. Hence from (31) we can have two possible sub-cases:

$c_{a 2}\left(b, q, p_{e}\right)<\widehat{c}(b)<c_{d}\left(b, p_{u}\right)$ : in this sub-case the set of individuals staying in period two and staying in three is empty since individuals migrate in period one when $c_{i}<c_{a 2}\left(b, q, p_{e}\right)$. For $c_{i}>c_{a 2}\left(b, q, p_{e}\right)$ it is optimal not to migrate already in the first place.

$\widehat{c}(b)<c_{a 2}\left(b, q, p_{e}\right)<c_{d}\left(b, p_{u}\right)$ : individuals with $c_{i} \in\left(\widehat{c}(b), c_{a 2}\left(b, q, p_{e}\right)\right)$ migrate in period one, return in period two. We observe that, for the non-empty subcase, all immigrants already return in the second period, if unemployed. It can be verified that the main insights of the model are still in play. Indeed, the elasticity w.r.t. $b$ of the stayers in period two and three are higher than the one of the migrants in the first period.

We now look at the case $\widehat{c}(b)>c_{d}\left(b, p_{u}\right)$, i.e. stay in period two and stay in period three. It follows from (30) that $c_{a 1}\left(b, q, p_{e}\right)>c_{a 2}\left(b, q, p_{e}\right) \Leftrightarrow 2 c_{a 2}\left(b, q, p_{e}\right)-$ $c_{a 1}\left(b, q, p_{e}\right)>c_{d}\left(b, p_{u}\right)$. This implies that $c_{a 2}\left(b, q, p_{e}\right)<c_{a 2}\left(b, q, p_{e}\right)-c_{a 1}\left(b, q, p_{e}, p_{u}\right)<$

\footnotetext{
${ }^{31}$ Indeed, from (29) and from the definition of $\widehat{c}(b)$ we have that

$U\left(w^{h}-\widehat{c}(b)-c_{a 1}\left(b, q, p_{e}, p_{u}\right)-U\left(w^{h}-2 c_{a 2}\left(b, q, p_{e}\right)\right)<U\left(w^{h}-\widehat{c}(b)-c_{d}\left(b, p_{u}\right)\right)-U\left(w^{h}-\right.\right.$ $\left.2 c_{d}\left(b, q, p_{e}\right)\right)$

We know that $c_{a 1}\left(b, q, p_{e}, p_{u}\right)<c_{a 2}\left(b, q, p_{e}\right)$. Moreover, let's assume that the left hand side of the above inequality is negative, i.e. $U\left(w^{h}-\widehat{c}(b)-c_{a 1}\left(b, q, p_{e}, p_{u}\right)-U\left(w^{h}-2 c_{a 2}\left(b, q, p_{e}\right)\right)<0\right.$ , i.e. $w^{h}-\widehat{c}(b)-c_{a 1}\left(b, q, p_{e}, p_{u}\right)<w^{h}-2 c_{a 2}\left(b, q, p_{e}\right),-\widehat{c}(b)-c_{a 1}\left(b, q, p_{e}, p_{u}\right)<-2 c_{a 2}\left(b, q, p_{e}\right)$, $c_{a 1}\left(b, q, p_{e}, p_{u}\right)>2 c_{a 2}\left(b, q, p_{e}\right)-\widehat{c}(b)$. For the inequality to hold, it follows that the rigth hand side of the previous expression has to be positive, i.e.

$U\left(w^{h}-\widehat{c}(b)-c_{d}\left(b, p_{u}\right)\right)-U\left(w^{h}-2 c_{d}\left(b, p_{u}\right)\right)>0$ implying that $\widehat{c}(b)<c_{d}\left(b, p_{u}\right)$. Hence, when $c_{a 1}\left(b, q, p_{e}, p_{u}\right)<c_{a 2}\left(b, q, p_{e}\right)$ and $c_{a 1}\left(b, q, p_{e}, p_{u}\right)>2 c_{a 2}\left(b, q, p_{e}\right)-\widehat{c}(b)$, then $c_{d}\left(b, p_{u}\right)>\widehat{c}(b)$. Analogously,we can now show that the opposite holds: when $c_{a 1}\left(b, q, p_{e}, p_{u}\right)>c_{a 2}\left(b, q, p_{e}\right)$ and

$c_{a 1}\left(b, q, p_{e}, p_{u}\right)<2 c_{a 2}\left(b, q, p_{e}\right)-\widehat{c}(b)$, then $c_{d}\left(b, p_{u}\right)<\widehat{c}(b)$.Hence,

$c_{a 1}\left(b, q, p_{e}, p_{u}\right) \lesseqgtr c_{a 2}\left(b, q, p_{e}\right), 2 c_{a 2}\left(b, q, p_{e}\right)-\widehat{c}(b) \lesseqgtr c_{a 1}\left(b, q, p_{e}, p_{u}\right) \Longrightarrow c_{d}\left(b, p_{u}\right) \lesseqgtr \widehat{c}(b)$. Note that $c_{d}\left(b, p_{u}\right)>\widehat{c}(b)$ is the case with return in period two and stay in period three and $c_{d}\left(b, p_{u}\right)<\widehat{c}(b)$. is the case with stay in periods two and three.
} 
$c_{a 1}\left(b, q, p_{e}, p_{u}\right)$. From this inequality and from (30) we can now have the following sub-cases ${ }^{32}$ :

$c_{d}\left(b, p_{u}\right)<c_{a 1}\left(b, q, p_{e}, p_{u}\right)<\widehat{c}(b)$ : since $c_{a 1}\left(b, q, p_{e}\right)<\widehat{c}(b)$, the set of individuals staying in period three (after having migrated in period one and stayed in two) is empty.

$c_{a 1}\left(b, q, p_{e}\right)<c_{d}\left(b, p_{u}\right)<\widehat{c}(b)$ : in this case the set of individuals staying in two and staying in three is empty since individuals migrate in one when $c_{i}<c_{a 1}\left(b, q, p_{e}, p_{u}\right)$. For $c_{i}>c_{a 1}\left(b, q, p_{e}, p_{u}\right)$ it is optimal not to migrate already in the first place. Hence, both sub-cases are empty.

To sum up, when $c_{i}>\widehat{c}(b)$, the only non-empty sub case is such that all individuals already return in period two in case of unemployment.

\subsubsection{Case: $c_{i}<\widehat{c}(b)$}

We analyse the case where the individual leaves in the third period in case of job loss. If the individual is unemployed in the second period, the return migration decision depends on

$U\left(b-c_{i}\right)+\frac{1}{1+\delta}\left[p_{u} U(w)+\left(1-p_{u}\right) U\left(w^{h}-c_{i}\right)\right] \lesseqgtr U\left(w^{h}-2 c_{i}\right)+\frac{1}{1+\delta} U\left(w^{h}\right)$

This defines a critical cost level

$$
c_{f}\left(p_{u}\right)
$$

by

$U\left(b-c_{f}\right)+\frac{1}{1+\delta}\left[p_{u} U(w)+\left(1-p_{u}\right) U\left(w^{h}-c_{f}\right)\right]=U\left(w^{h}-2 c_{f}\right)+\frac{1}{1+\delta} U\left(w^{h}\right)$

The new twist here is that some may decide to stay in period two even though they leave in three (if they don't get a job). This applies if

$$
c_{f}\left(p_{u}\right)<c_{i}<\widehat{c}(b)
$$

We define $c_{b 1}\left(b, q, p_{e}, p_{u}\right)$ as the cost making the individual indifferent between migrating in the first period (staying in period two and returning in three) and not migrating as

$$
\begin{aligned}
& q\left[U\left(w-c_{b 1}\left(b, q, p_{e}, p_{u}\right)\right)+\frac{1}{1+\delta}\left[p_{e} U(w)+\left(1-p_{e}\right) U\left(w^{h}-c_{b 1}\left(b, q, p_{e}, p_{u}\right)\right)\right]\right] \\
& +(1-q)\left\{U\left(b-c_{b 1}\left(b, q, p_{e}, p_{u}\right)\right)+\frac{1}{1+\delta}\left[p_{u} U(w)+\left(1-p_{u}\right) U\left(w^{h}-c_{b 1}\left(b, q, p_{e}, p_{u}\right)\right)\right]\right\} \\
= & U\left(w^{h}\right)+\frac{1}{1+\delta} U\left(w^{h}\right)
\end{aligned}
$$

\footnotetext{
${ }^{32}$ Observe that now the benchmark cost for the migration decision in the first place is $c_{a 1}\left(b, q, p_{e}\right)$.
} 
For those returning in period two, we define $c_{b 2}\left(q, p_{e}\right)$ as the threshold cost making individuals indifferent between migrating in period one (and returning in period two) and not migrating as

$$
\begin{aligned}
& q\left[U\left(w-c_{b 2}\left(q, p_{e}\right)\right)+\frac{1}{1+\delta}\left[p_{e} U(w)+\left(1-p_{e}\right) U\left(w^{h}-c_{b 2}\left(q, p_{e}\right)\right)\right]\right] \\
& +(1-q)\left\{U\left(w_{h}-2 c_{b 2}\left(q, p_{e}\right)\right)+\frac{1}{1+\delta} U\left(w^{h}\right)\right\} \lesseqgtr U\left(w^{h}\right)+\frac{1}{1+\delta} U\left(w^{h}\right)
\end{aligned}
$$

Taking the difference between $c_{b 1}\left(b, q, p_{e}, p_{u}\right)$ and $c_{b 2}\left(q, p_{e}\right)$ we have that

$$
\begin{aligned}
& q\left[(1+\delta) U\left(w-c_{b 1}\left(b, q, p_{e}, p_{u}\right)\right)+p_{e} U(w)+\left(1-p_{e}\right) U\left(w^{h}-c_{b 1}\left(b, q, p_{e}, p_{u}\right)\right)\right] \\
& +(1-q)\left\{(1+\delta) U\left(b-c_{b 1}\left(b, q, p_{e}, p_{u}\right)\right)+p_{u} U(w)+\left(1-p_{u}\right) U\left(w^{h}-c_{b 1}\left(b, q, p_{e}, p_{u}\right)\right)\right\}- \\
& q\left[(1+\delta) U\left(w-c_{b 2}\left(q, p_{e}\right)\right)+p_{e} U(w)+\left(1-p_{e}\right) U\left(w^{h}-c_{b 2}\right)\right]- \\
& -(1-q)\left[(1+\delta) U\left(w^{h}-2 c_{b 2}\left(q, p_{e}\right)\right)+U\left(w^{h}\right)\right]
\end{aligned}
$$

Suppose that $c_{b 1}\left(b, q, p_{e}, p_{u}\right)>c_{b 2}\left(q, p_{e}\right)$, i.e.

$$
\begin{aligned}
& (1-q)\left((1+\delta)\left[U\left(b-c_{b 1}\left(b, q, p_{e}, p_{u}\right)\right)-U\left(w^{h}-2 c_{b 2}\left(q, p_{e}\right)\right)\right]+\right. \\
& \left.+p_{u} U(w)+\left(1-p_{u}\right) U\left(w^{h}-c_{b 1}\left(b, q, p_{e}, p_{u}\right)\right)+U\left(w^{h}\right)\right) \\
> & q\left((1+\delta)\left[U\left(w-c_{b 2}\left(q, p_{e}\right)\right)-U\left(w-c_{b 1}\left(b, q, p_{e}, p_{u}\right)\right)\right]+\right. \\
& \left.+\left(1-p_{e}\right)\left[U\left(w^{h}-c_{b 2}\left(q, p_{e}\right)\right)-U\left(w^{h}-c_{b 1}\left(b, q, p_{e}, p_{u}\right)\right)\right]\right)
\end{aligned}
$$

Hence, the right hand side is positive since $U\left(w-c_{b 2}\left(q, p_{e}\right)\right)-U\left(w-c_{b 1}\left(b, q, p_{e}, p_{u}\right)\right)>$ 0 and $U\left(w^{h}-c_{b 2}\left(q, p_{e}\right)\right)-U\left(w^{h}-c_{b 1}\left(b, q, p_{e}, p_{u}\right)\right)>0$. Hence, also the left hand side

$(1-q)\left((1+\delta)\left[U\left(b-c_{b 1}\left(b, q, p_{e}, p_{u}\right)\right)-U\left(w^{h}-2 c_{b 2}\left(q, p_{e}\right)\right)\right]+p_{u} U(w)+(1-\right.$ $\left.\left.p_{u}\right) U\left(w^{h}-c_{b 1}\left(b, q, p_{e}, p_{u}\right)\right)+U\left(w^{h}\right)\right)$ has to be positive. Observe that it can be verified that this is always satisfied for $c_{b 1}\left(b, q, p_{e}, p_{u}\right)$ lower than a threshold value and for any values of $\widehat{c}(b)$ and $c_{f}\left(p_{u}\right)$. Hence, we firstly consider the case of stay in period two in case of unemployment (and return in period three), i.e. $c_{f}\left(p_{u}\right)<\widehat{c}(b)$. This case is compatible with $c_{b 1}\left(b, q, p_{e}, p_{u}\right) \lesseqgtr c_{b 2}\left(q, p_{e}\right)$. The only condition that has to be satisfied is that $c_{f}\left(p_{u}\right)<c_{b 1}\left(b, q, p_{e}, p_{u}\right)^{33}$. Specifically, we can identify two migration regimes.

Regime I: $c_{f}\left(p_{u}\right)<c_{b 1}\left(b, q, p_{e}, p_{u}\right)<\widehat{c}(b)$. In this regime, all immigrants staying in the second period in case if unemployment also return in the third period if unemployed (this resembles regime I of the benchmark model where all immigrants return in case of unemployment). Specifically, individuals with

\footnotetext{
${ }^{33}$ Indeed, if $c_{b 1}\left(b, q, p_{e}, p_{u}\right)<c_{f}\left(b, p_{u}\right)$, only individuals with $c_{i}<c_{b 1}\left(b, q, p_{e}, p_{u}\right)$ migrate. Hence, the set of individuals staying in period two if unemployed, i.e. individuals with $c_{i}>$ $c_{f}\left(b, p_{u}\right)$ is empty since they do not migrate in the first period.
} 
$c_{i} \in\left(\underline{c}, c_{b 1}\left(b, q, p_{e}, p_{u}\right)\right)$ migrate in the first period and individuals with $c_{i} \in$ $\left(c_{f}\left(p_{u}\right), c_{b 1}\left(b, q, p_{e}, p_{u}\right)\right)$ stay in the second period in case of job loss. In the third period, individuals with $c_{i} \in\left(c_{f}\left(p_{u}\right), c_{b 1}\left(b, q, p_{e}, p_{u}\right)\right)$ return in case of unemployment.

Regime II: $c_{f}\left(p_{u}\right)<\widehat{c}(b)<c_{b 1}\left(b, q, p_{e}, p_{u}\right)$. In this regime not all immigrants staying in period two in case of unemployment return in period three. The fraction of immigrants and stayers in the second period in case of unemployment is analogous to regime I. Instead, the fraction of returnees in case of job loss is given by $c_{i} \in\left(c_{f}\left(p_{u}\right), \widehat{c}(b)\right)$. In both regimes immigrants in the first period stay in the second period if unemployed. As in the basic model, the elasticity w.r.t. $b$ of the stayers in period two is higher than of the one of the immigrants.

To sum up, in regime I, all immigrants staying in the second period return in the third period if unemployed, while in regime II some of the stayers in period two return in period three. In regime II, the elasticity of the stayers is higher than the one of the migrants.

Let's now consider the case where $c_{f}\left(p_{u}\right)>\widehat{c}(b)$, namely the case where individuals return in the second period. As before, this case is compatible with $c_{b 1}\left(b, q, p_{e}, p_{u}\right) \lessgtr c_{b 2}\left(q, p_{e}\right)$. In this case, we can identify two possible sub-cases. Regime I: $c_{b 2}\left(q, p_{e}\right)<\widehat{c}(b)<c_{f}\left(p_{u}\right)$ or $\widehat{c}(b)<c_{b 2}\left(q, p_{e}\right)<c_{f}\left(p_{u}\right)$. In this migration regime, all immigrants return in period two and three in case of unemployment. Indeed, individuals with $c_{i} \in\left(\underline{c}, c_{b 2}\left(q, p_{e}\right)\right)$ migrate in the first period and already return in the second period if unemployed.

Regime II: $\widehat{c}(b)<c_{f}\left(p_{u}\right)<c_{b 2}\left(q, p_{e}\right)$ In this migration regime, individuals with $c_{i}<c_{b 2}\left(q, p_{e}\right)$ migrate in the first period. Among them, only individuals

with $c_{i} \in\left(\underline{c}, c_{f}\left(p_{u}\right)\right)$ return in the second period in case of unemployment and only the ones with $c_{i} \in(\underline{c}, \widehat{c}(b))$ return in the third period.

\subsection{General equilibrium and path dependence}

The model is set-up as a partial equilibrium model to allow a presentation of the main result as simple as possible. The key finding is the possible path dependence in worker migrant flows, and this finding will carry over to more general settings. A global general equilibrium analysis would have to take a stand on long-run migration flows, and even though such flows may persist in a stationary equilibrium (as they do in e.g. search matching models) it is of interest to consider how migration flows may be considered as an adjustment mechanisms towards stationary equilibrium, i.e. a "disequilibrium" phenomenon.

To consider this scenario return to the determination of the critical costs levels when wages may temporarily deviate from the long run level. To capture this assume that wages in the home country may differ between the first and second period ( $w_{1}$ and $w_{2}$, respectively). The critical cost level $\widehat{c}(b)$ is unchanged, while $c_{a}\left(b, p, w_{1}, w_{2}\right)$ is now determined by

$U\left(w^{h}\right)+\frac{1}{1+\delta} U\left(w^{h}\right)=U\left(w_{1}-c_{a}\left(b, p, w_{1}, w_{2}\right)\right)+\frac{1}{1+\delta}\left[p U\left(w_{2}\right)+(1-p) U(b)\right]$ 
and $c_{b}\left(p, w_{1}, w_{2}\right)$ as

$U\left(w^{h}\right)+\frac{1}{1+\delta} U\left(w^{h}\right)=U\left(w_{1}-c_{b}\left(p, w_{1}, w_{2}\right)\right)+\frac{1}{1+\delta}\left[p U\left(w_{2}\right)+(1-p) U\left(w^{h}-c_{b}\left(p, w_{1}, w_{2}\right)\right)\right]$

It follows that both $c_{a}\left(b, p, w_{1}, w_{2}\right)$ and $c_{b}\left(p, w_{1}, w_{2}\right)$ are increasing in $w_{1}$ and $w_{2}$. It is also easily checked that we still have

$$
c_{a}\left(b, p, w_{1}, w_{2}\right) \gtreqless c_{b}\left(p, w_{1}, w_{2}\right) \text { for } \widehat{c}(b) \lesseqgtr c_{b}\left(p, w_{1}, w_{2}\right)
$$

Consider now a case where the economy initially is in steady state equilibrium and where Foreign and Home are symmetric, meaning that $w_{1}=w_{2}=w=w^{h}$. At these wages, $\underline{c}>c_{a}(b, p, w, w)$ and $\underline{c}>c_{b}(p, w, w)$ there is no migration. Indeed, since Foreign and Home are symmetric, there is no incentive to migrate to Foreign ${ }^{34}$. Suppose now that the wage in the first period $w_{1}$ increases above $w^{h}$. Obviously, such an increase is large enough to release worker migration if $\underline{c}>c_{a}\left(b, p, w_{1}, w_{2}\right)$ and/or $\underline{c}>c_{b}\left(p, w_{1}, w_{2}\right)$. The interesting question is whether migration flows release effects lasting longer than the shock, i.e. are persistence mechanisms released by worker migration. If we are in regime I $\left(\widehat{c}(b)>c_{b}\left(p, w_{1}, w_{2}\right)\right)$ there will be persistence unless all migrants are laid-off in period two when the shock disappears $(p=0)$, if not some migrants will remain in the country and the labour force is not only affected in the first period, i.e. there is persistence. If we are in regime II $\left(\widehat{c}(b)<c_{b}\left(p, w_{1}, w_{2}\right)\right)$ then there is persistence even if migrant workers are laid-off $(p=0)$ when the underlying shock redresses, since some unemployment migrant workers will remain in the country. The finding that migration responds asymmetrically to shocks and thus is associated with persistence or path dependence is thus general, although the general equilibrium effects will be more complicated than sketched here (among other things wages will be endogenous).

\footnotetext{
${ }^{34}$ Indeed, if $w_{1}=w_{2}=w=w^{h}$, the critical cost level $c_{a}(b, p, w, w)$ is determined as $U(w)+\frac{1}{1+\delta} U(w)=U\left(w-c_{a}(b, p, w, w)\right)+\frac{p U(w)}{1+\delta}+\frac{(1-p) U(b)}{1+\delta}$. In the linear case, here considered for simplicity, this implies that $(2+\delta-p) w=(1+\delta)\left(w-c_{a}(b, p, w, w)\right)+(1-p)(b)$ which simplifies to $(1-p)(w-b)=-c_{a}(b, p, w, w)(1+\delta)$. Since all the individual costs $c_{i}$ are positive and $c_{a}(b, p, w, w)$ is now negative (since $w>b$ ), we have that $c_{i}>c_{a}(b, p, w, w)$ for all individuals. Therefore, the expected utility of not migrating is always higher than the expected utility of migrating and staying. The condition making the individual indifferent between not migrating and migrating-returning is given by $U(w)+\frac{U(w)}{1+\delta}=U\left(w-c_{b}(p, w, w)\right)+$ $\frac{p U(w)}{1+\delta}+\frac{(1-p)\left(U\left(w-c_{b}(p, w, w)\right)\right.}{1+\delta}$ that, in the linear case, simplifies to $0=-c_{b}(p, w, w)(2+\delta-p)$. Following the same reasoning as before, the utility of not migrating is greater than the utility of migrating and returning for all the individuals $i$. Hence, in the initial steady state $\left(w_{1}=\right.$ $\left.w_{2}=w\right)$ where Foreign and Home are symmetric $\left(w=w^{h}\right)$, migration does not occur.
} 